ص ص ص

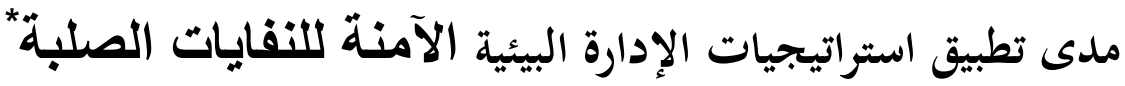

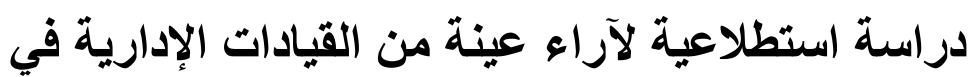 مديرية بلاية الموصلة من العاد
}

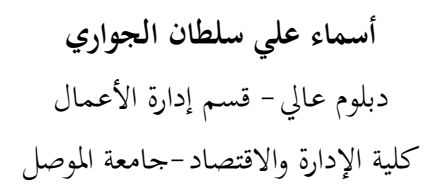

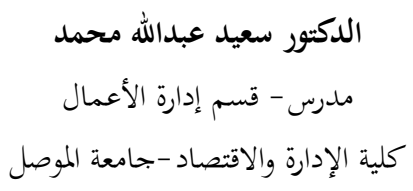

allsaied@yahoo.com

\section{المستخلص}

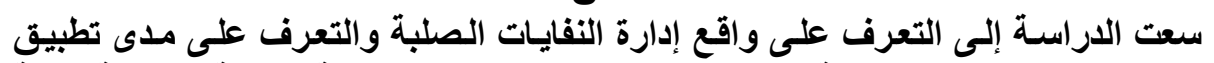

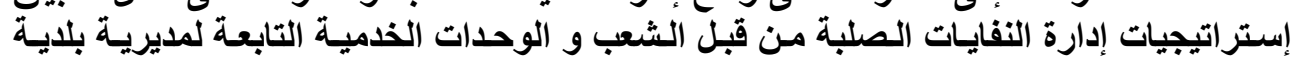

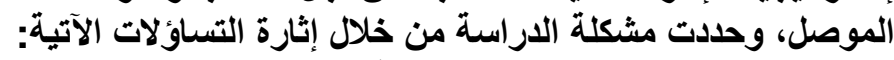

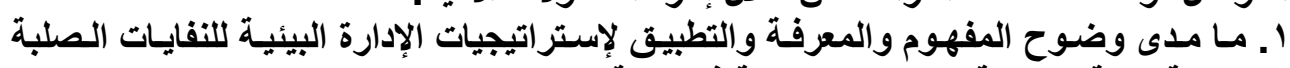

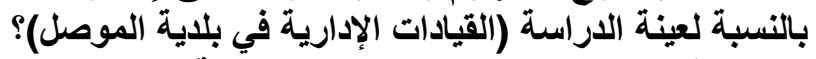

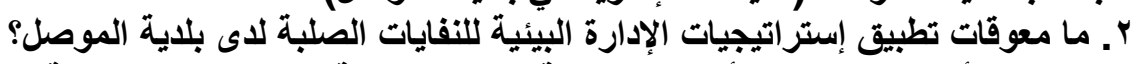

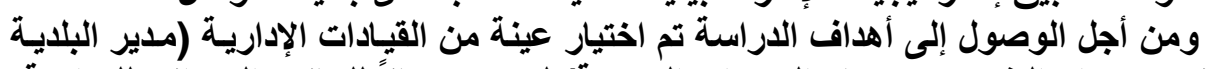

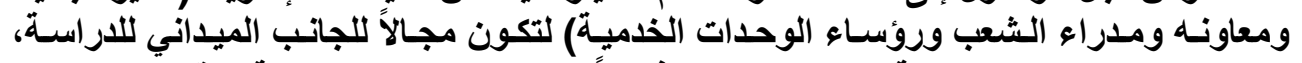

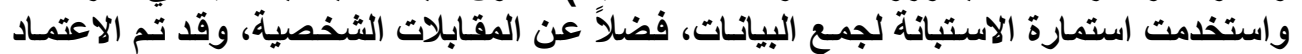

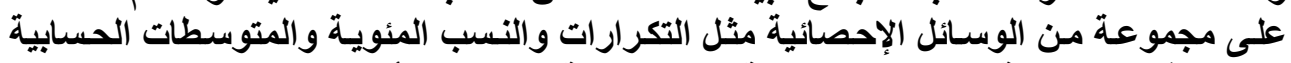

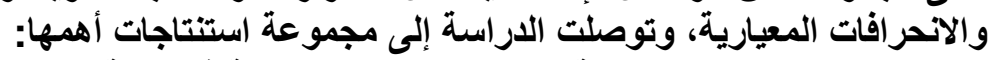

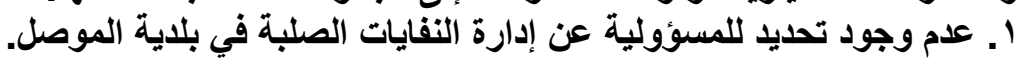

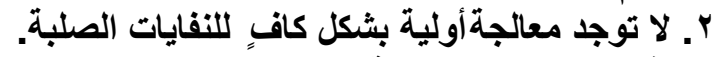

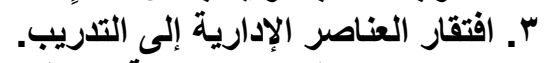

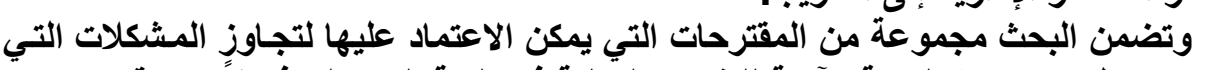

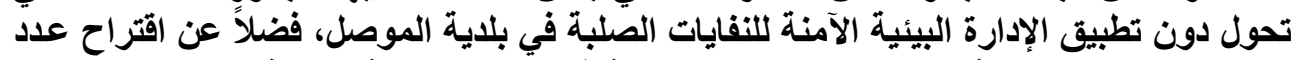

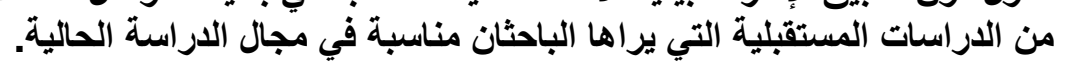

الكلمات المفتاحية: الإدارة الإستراتيجية، الإدارة البيئية، البيئة، إستراتيجيات الإدارة البيئية.

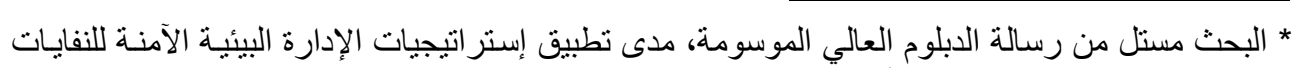

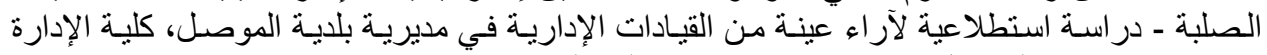

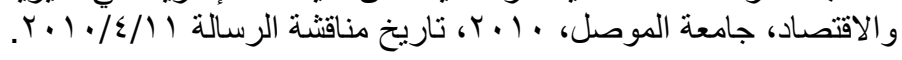

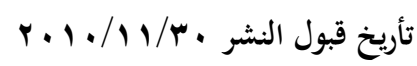

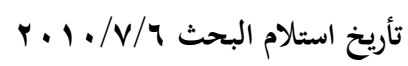




\title{
The Extent of Implementation of Safety Environmental Management Strategies of Solid Waste \\ A Pilot Study For Opinions Of A Sample Of Administrative Leadership In Mosul Municipality Directorate
}

\author{
Saied A. Mohammed (PhD) \\ Lecturer \\ Department of Business Administration \\ University of Mosul
}

\author{
Asmaa' Ali Sultan Al-Juwari \\ High Diploma \\ Department of Business Administration \\ University of Mosul
}

\begin{abstract}
The study sought to identify the reality of solid waste management and to identify the extent of solid waste management application strategies by the people or service units of the Directorate of Mosul Municipality, the study identified the problem by raising the following questions:

1. To what extent and clarity of the concept and application of knowledge and strategies for environmental management of solid waste?

2. What are the obstacles to the application of environmental management strategies for municipal solid waste in Mosul?

In order to reach the objectives of the study, a sample was selected from the administrative leadership (Director of the municipality and the deputy and division directors and heads of service units) to be room for the field of study. The study used a form of questionnaire to collect data, as well as personal interviews, relied on a set of statistical tools such as frequencies, percentages, averages and standard deviations. The study found the most important conclusions of the following:

1. Lack of definition of the responsibility for managing solid waste in the municipality of Mosul.

2. No preliminary treatment is enough for solid waste.

3. Lack of administrative elements to the training.

The study research included a set of proposals that can be relied upon to overcome the problems that prevent the safe application of environmental management of solid waste in the municipality of Mosul, as well as proposing a number of future studies as it deems appropriate researchers in the field of the present study.
\end{abstract}

Key Words: Strategic Management, Environmental Management, Environmental, Strategies Management Environmental.

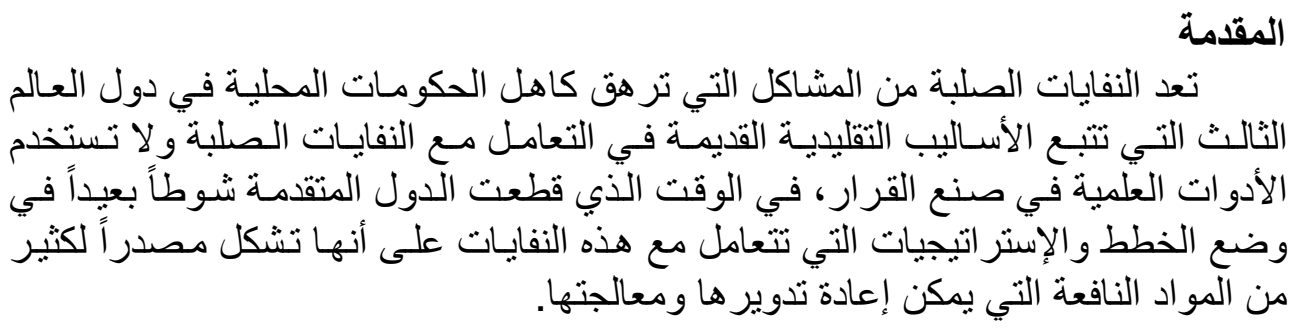




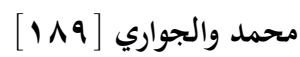

إن حجم الضرورة التـي تقتضـي بمعالجـة الفضلات في مدينـة الموصـل يتعـاظم مـع

الوقت وذللك للأسباب الآتبة:

• بسبب النمو السريع في عدد السكان السبة في التجمعات البشرية في المدينة.

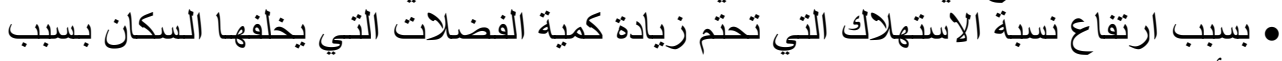

الأنشطة البشرية المختلفة.

• بسبب التحسن النسبي لاخل الفرد، الذي يؤدي إلى زيادة استهلاك المنتجات، وبما ينعكس

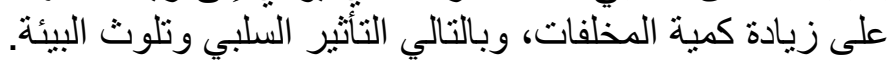

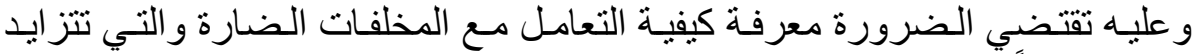

بشكل كبير وتحديداً النفايات الصلبة التي يمكن تدوير ها و إعادة استخدامها.

\section{منهجية البحث \\ مشكلة الدراسة الئة}

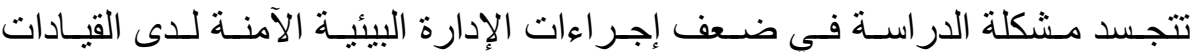

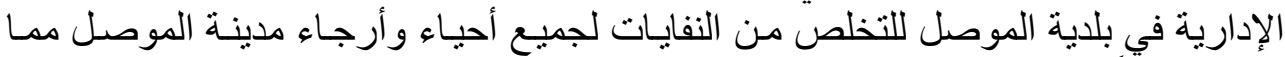

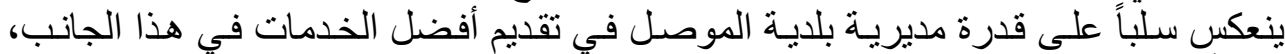

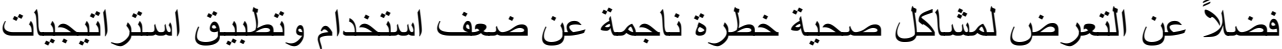
الإدارة البيئية السليمة، ويمكن طر ح مشكلة الدر اسة من خلائل التهائل التساؤلات الرئيسة الآتية:

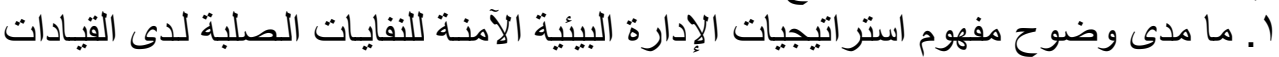

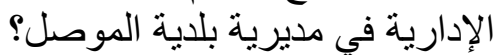

Y. هل تمتلك القيادات الإداريـة في مديريـة بلايـة الموصل المعرفة الكافية الكافية لاستر اتيجيات

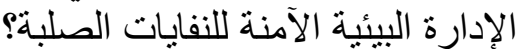

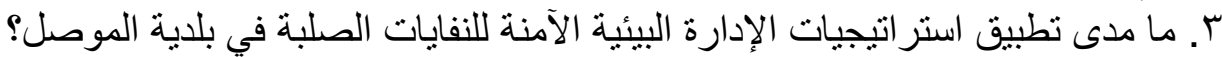

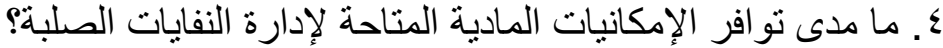
ه. ما معوقات تطبيق استر اتيجيات الإدارة البيئية الآمنـة للنفايـات الصلبة لـاتية لدى مديريـة بلديـة

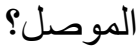

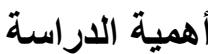

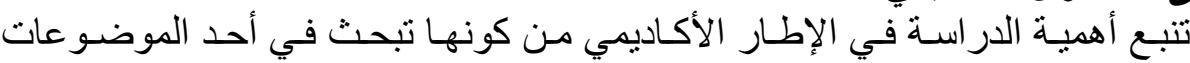

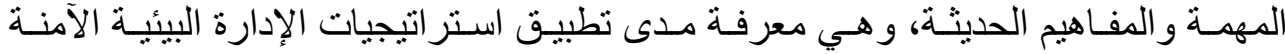

للنفايات الصلبة.

r. الأهمية على المستوى العملي الني

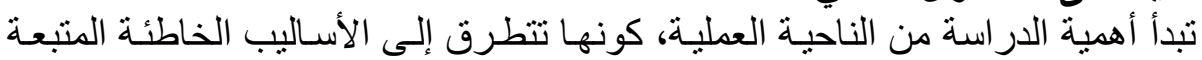

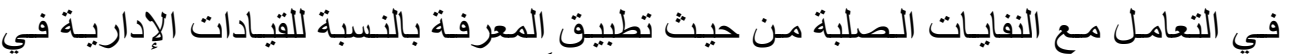

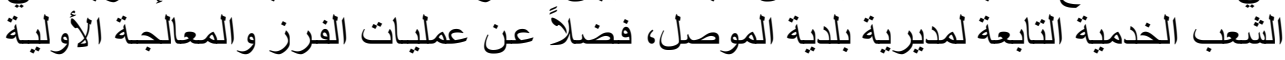
و المعالجات النهائية للنفايات الصنبة لبنة 


\section{r. الأهمية على المستوى الاقتصادي}

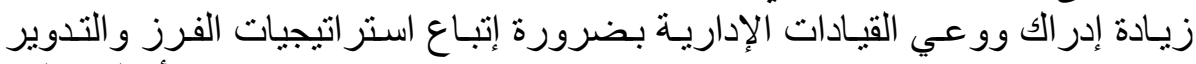

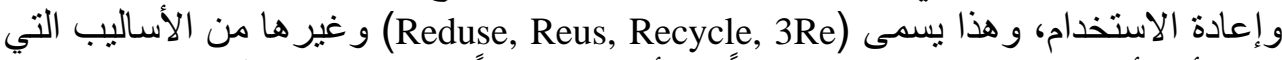

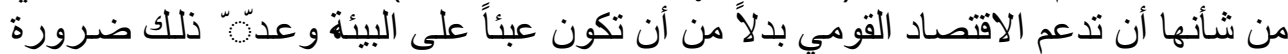

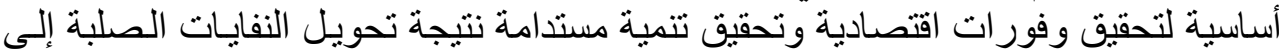

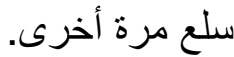

$$
\text { أهداف الدراسة }
$$

$$
\text { تهرف الدر اسة إلى تحقيق ما يأتي: }
$$

1. التعرف على مدى وضوح مفهوم استر اتيجيات الإدارة البيئية الآمنـة للنفايـات الصلبة

$$
\text { لاعى عينة الدر اسة. }
$$

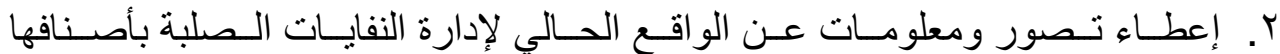

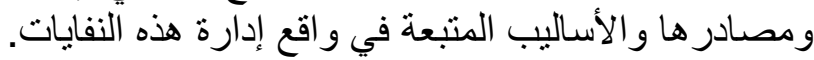

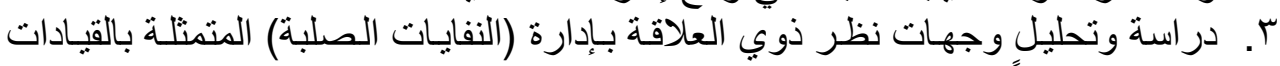

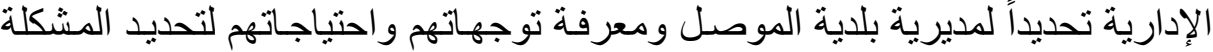
القائمة والوقوف عليها ومحاولة الوصول إلى الحل المناسب.

\begin{tabular}{|c|c|c|c|c|}
\hline \multicolumn{5}{|c|}{ 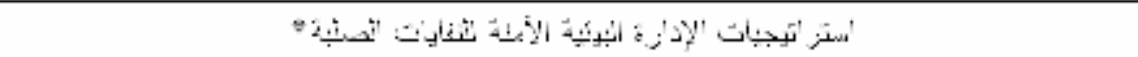 } \\
\hline 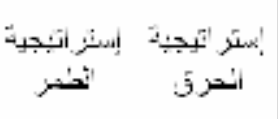 & 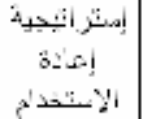 & 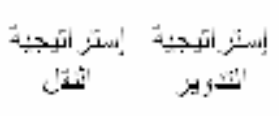 & 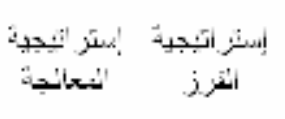 & 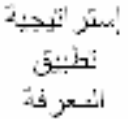 \\
\hline
\end{tabular}

$$
\begin{aligned}
& \text { مخطط الدراسة الافتر اضي }
\end{aligned}
$$

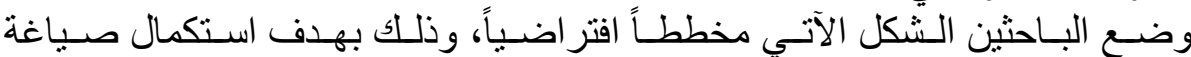

$$
\begin{aligned}
& \text { فرضيات البحث. }
\end{aligned}
$$
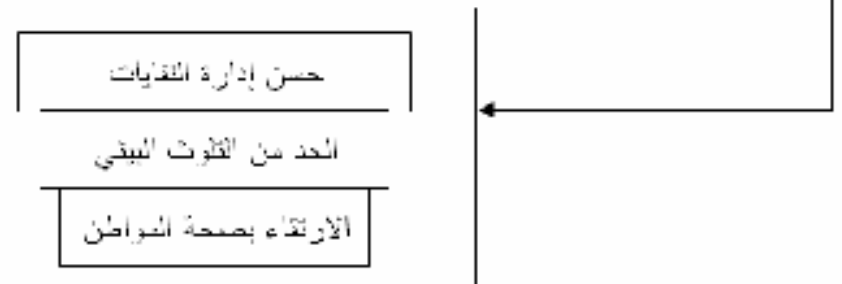

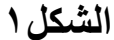

مخطط الاراسة الافتراضي اضمي

* سيتم توضيح الاستر اتيجيات المعتمة في المخطط لاحقاً 
محمد والجواري [19 [19]

$$
\text { فرضيات الأراسة }
$$

عدم وجود وضوح تام لاستر اتيجيات الإدارة البيئية الآمنة للنفايات الصلبة لدى أغلب

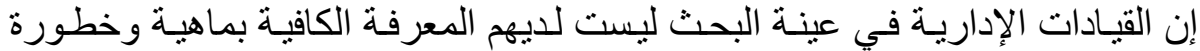

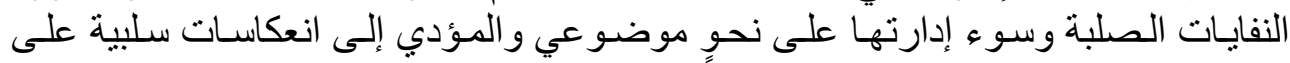
صحة الإنسان.

\section{الفرضية الثالثة}

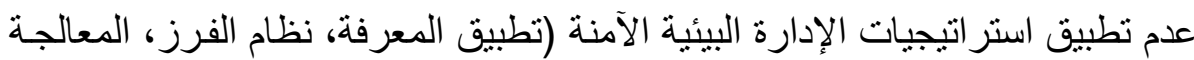

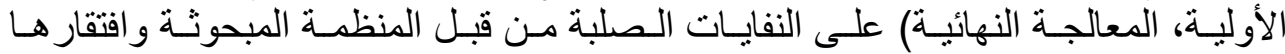
للأساليب العلمية الآمنة للتعامل مع النفايات الصلبة.

وجود معوقات إداريـة وفنيـة وماديـة تعيق تطبيق استر اتيجيات الإدارة البيئية الآمنـة

$$
\text { الفرضية الرابعة }
$$

للنفايات الصلبة.

$$
\text { أساليب جمع البيانات }
$$

من أجل الوصول البيات إلى هدف الدراسـة تم اختيـار العينـة لتكون مجـالاً للجانب الميداني

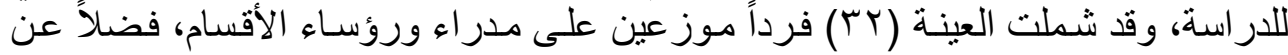

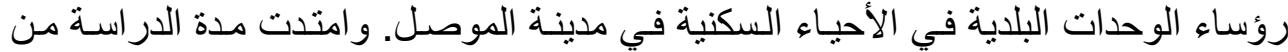

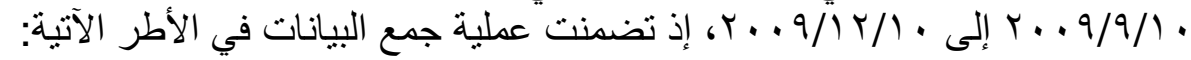

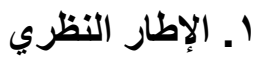

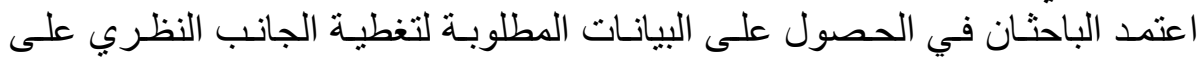

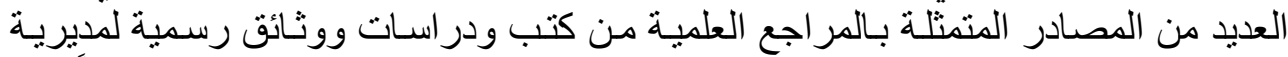

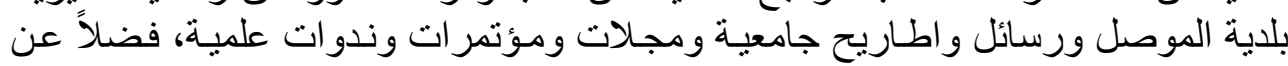
المصادر التي تم الحصول عليها من شبكة المعلومات العاتية العالمية (الانترنت). ب المقإِار الميداني

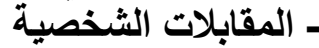

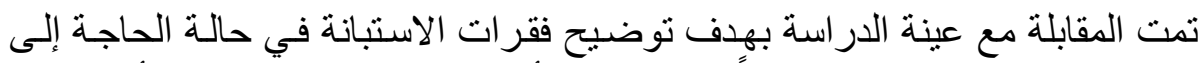

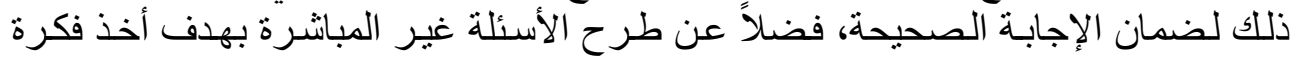

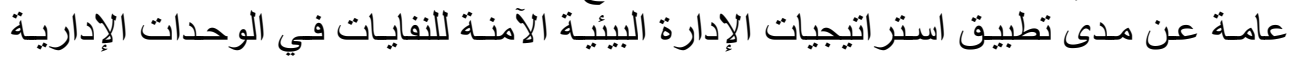

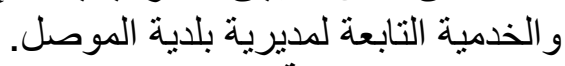
- استمارة الاستبانة

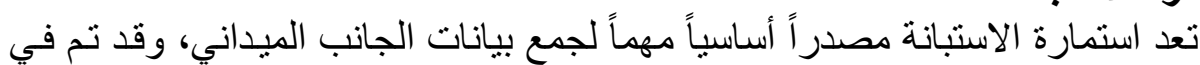

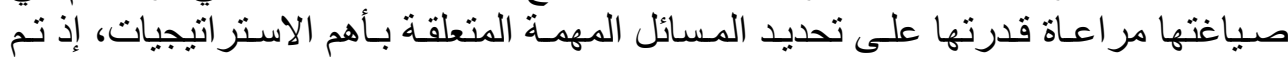

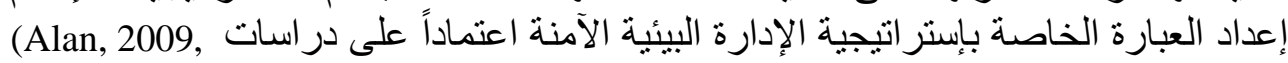




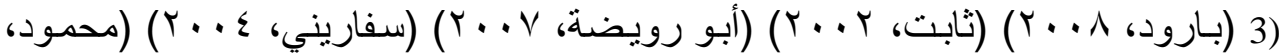

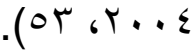

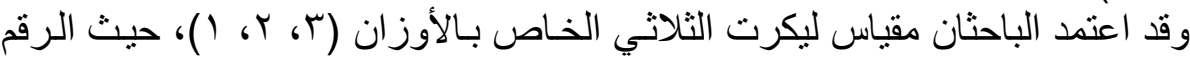

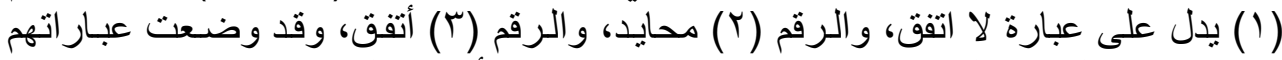

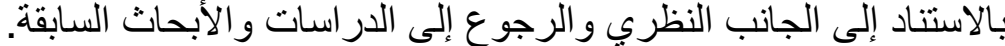

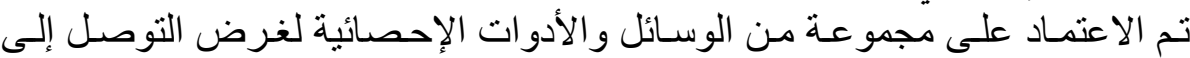

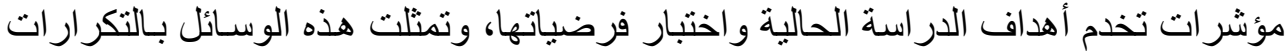

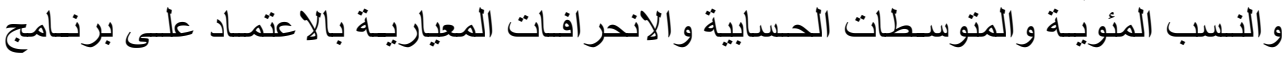

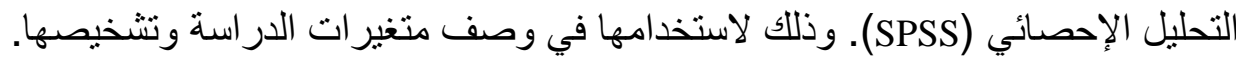

\section{الإطار النظري

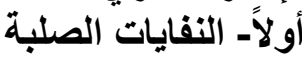

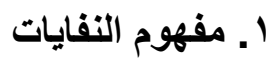

تعرف النفايات بأنها تلك المو اد التي تلقيها أو تولدها الكائنات الحيـة في النظام البيئي

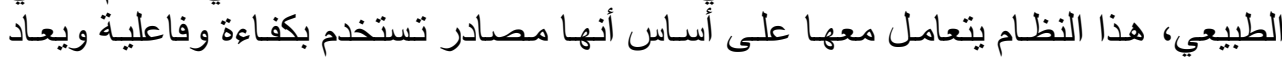

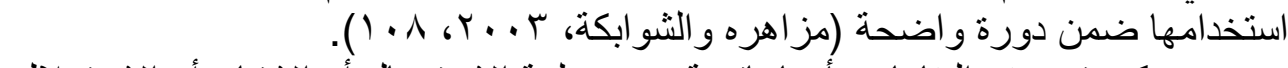

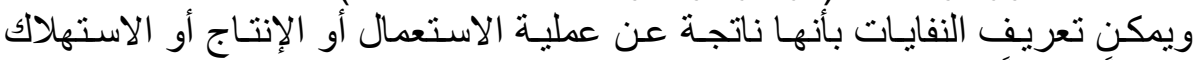

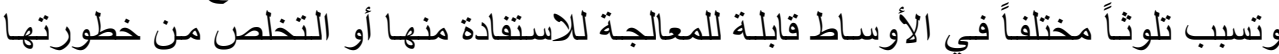

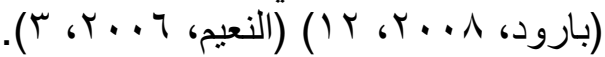

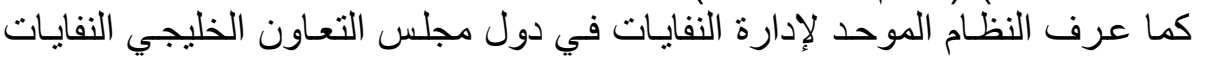

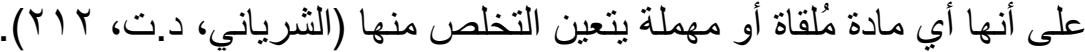

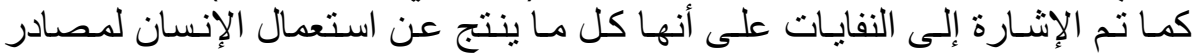

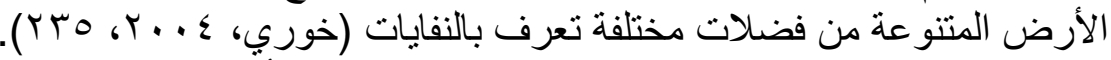

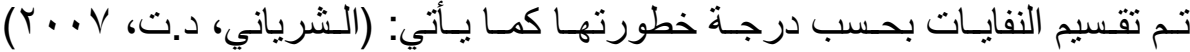

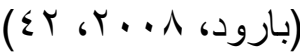
أ. النفايات غير الخطرة (الحميدة)

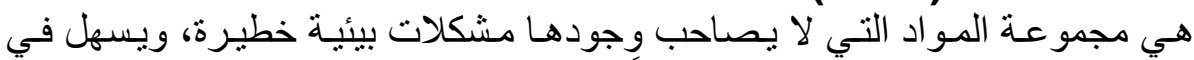

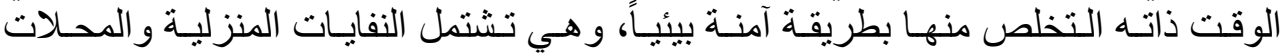
التجارية ونفايات المصانع غير الخطرة النغرة ب. النفايات الخطرة

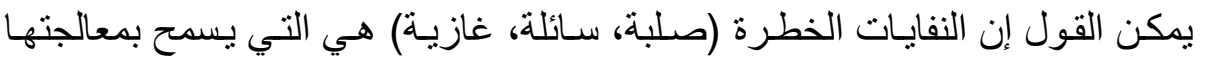
قانوناً في مجمعات النفايات ،وتعالج في وحدات مصنفة معتمدة من قبل السلطات النات المحلية. r ب مفهوم النفايات الصلبة

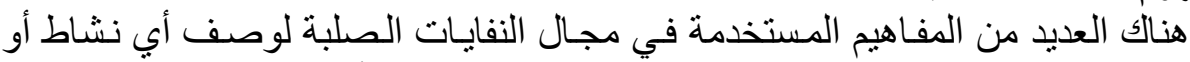

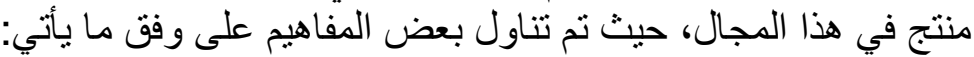

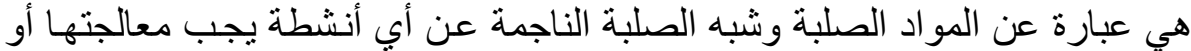

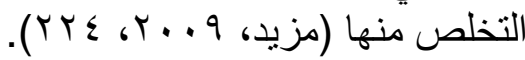




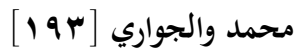

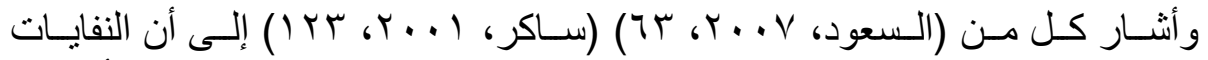

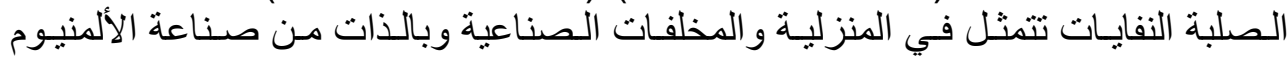

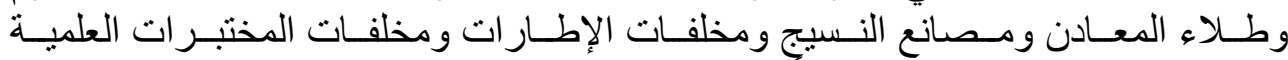

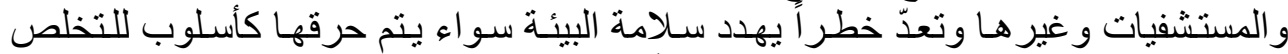

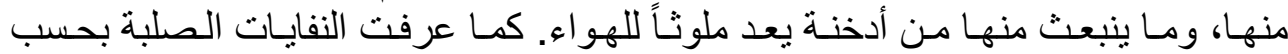

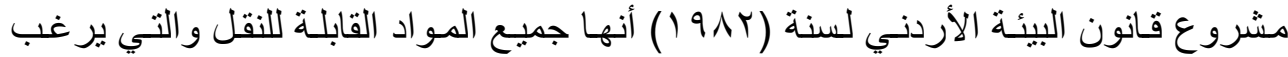

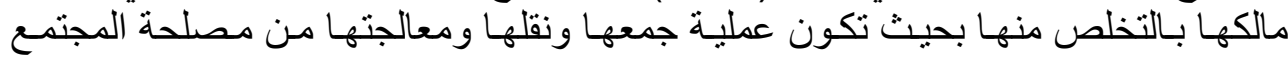

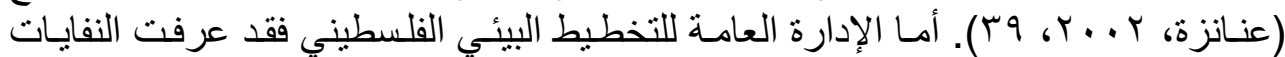

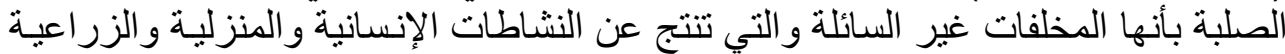
والصناعية والتجارية المركزية و الحرفية.

r. أنواع النفايات الصلبة ومصادرها

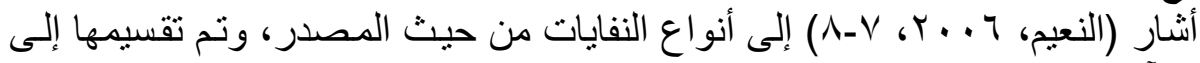

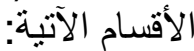

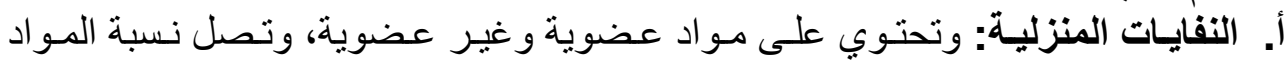

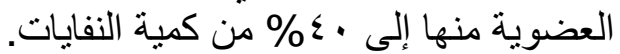

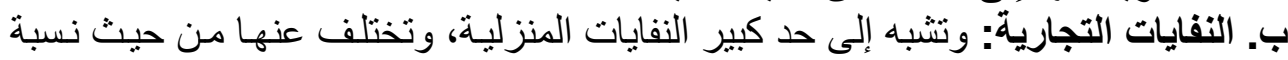
المكونات وكمية النفايات المنتجة. ت. النفايات الصناعية: ويمكن تقسيمها إلى نفايات صناعية غير خطرة ونفايـات صناعية خطرة. ث. النفايـات الطبية: وتشمل مجموعة مـن المخلفـات المُعديـة والخطرة والمخلفات الطبيـة

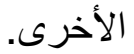

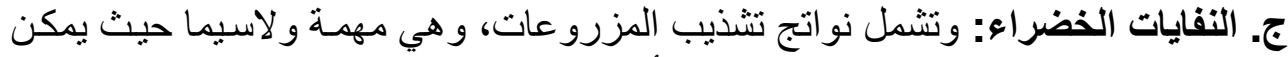

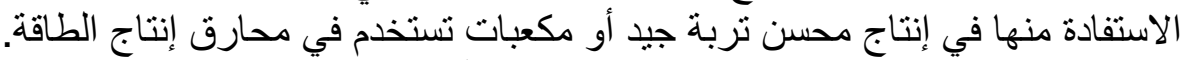

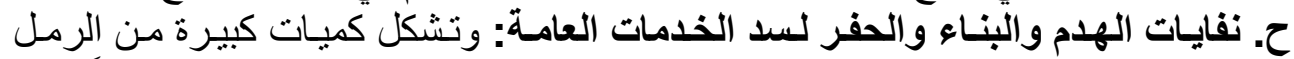

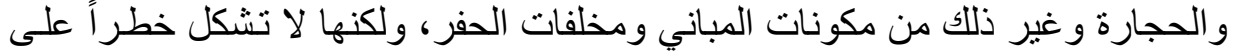
الصحة.

ثالثاً. معدلات توليد النفايات الصلبة في بعض الداول العبات العربية والأجنبية

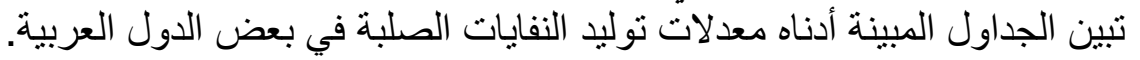

\section{الجدول 1}

معدل النفايات المنزلية الصلبة في دول المجلس مقارنة ببعض الدول الدول العربية

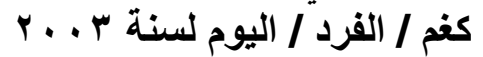

\begin{tabular}{|c|c|c|c|}
\hline \multicolumn{2}{|c|}{ بعض الدول العربية الأخرى } & \multicolumn{2}{|l|}{ دول المجلس } \\
\hline معدل النفايات كفم / فرد / يوم & الدولة - مالة & معدل النفايات كفم / فرد /يوم & الدولة - مالة \\
\hline$\cdot . \wedge 1$ & مصر & $1 . r$ & الإمارات \\
\hline$\cdot . \mu$ & 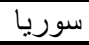 & $1 . r$ & البحرين \\
\hline - ६1 & تونس & $1 . \varepsilon$ & السعودية \\
\hline$\cdot \pi \mu$ & المغرب المب &.. $\mathrm{V}$ & عمان ( عمان \\
\hline
\end{tabular}




\begin{tabular}{|c|c|c|c|}
\hline \multicolumn{2}{|c|}{ بعض الدول العربية الأخرى } & \multicolumn{2}{|l|}{ دول المجلس } \\
\hline معدل النفايات كفم / فرد / يوم & الدولة & معدل النفايات كفم / فرد /يوم & الأولة \\
\hline$\cdot .7$ & الأردن & $1 . r$ & قطر \\
\hline$\cdot .7$ & اليمن & $1 . \varepsilon$ & الكويت \\
\hline .01 & المعدل & $\overline{1 . Y}$ & المعدل \\
\hline
\end{tabular}

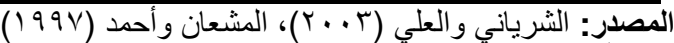

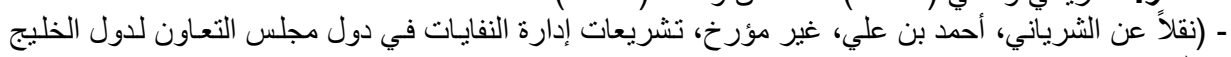

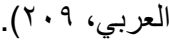

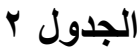

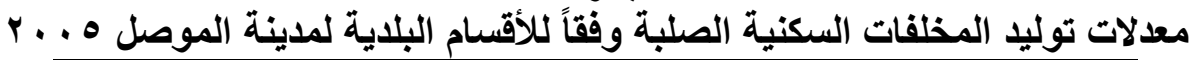

\begin{tabular}{|c|c|c|c|c|c|}
\hline \multicolumn{3}{|c|}{ الكمية على مستوى القسم البلدي (طن) } & \multirow{2}{*}{ 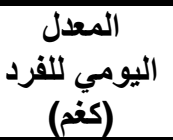 } & \multirow{2}{*}{ القسم البلدي } & \multirow{2}{*}{ ت } \\
\hline شهرياً & أسبوعياً & يومبياً & & & \\
\hline$V \leqslant V$ & IV $1 . r$ & $r \leq .9$ &..$r 7$. & 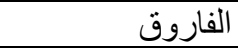 & 1 \\
\hline 019 & $1 Y 1.1$ & IV.r & .910 & فلسطين & r \\
\hline ros & $\Lambda Y .7$ & 11.1 &.$r T$. & 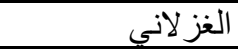 & $r$ \\
\hline 000 & 119.0 & 11.0 &. ro. & الحدباء & $\varepsilon$ \\
\hline 997 & TMT.E & r l &..$Y q$ & 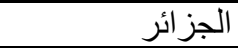 & 0 \\
\hline $79 \pi$ & 171.8 & r.I & $\cdot r \cdot$ & الخضر اء & 7 \\
\hline $7 r V$ & $1 \leq 7 . r$ & $r \cdot .9$ &. ro. & 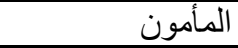 & $\mathrm{V}$ \\
\hline $00 \mathrm{r}$ & IY^.^ & $11 . \varepsilon$ &.$r$. & المنصور & $\wedge$ \\
\hline TYו & $1 \leq \varepsilon .9$ & $r \cdot . \mathrm{V}$ & $\cdot$. & القادسية & 9 \\
\hline 997 & TMY.E & r. &. & الربيع & 1 . \\
\hline 711 & $1 \leq \varepsilon . Y$ & $r \cdot .7$ &.$r q$. & الصديق & 11 \\
\hline 1.19 & $r \varepsilon \cdot .1$ & $r \varepsilon . r$ &.$r \wedge$. & الوحدة & ir \\
\hline $11 \leqslant r$ & Y77.V & rᄉ. &. ro. & اليرموك & $1 \pi$ \\
\hline$r \cdot \vee q$ & $\sum \wedge 0.1$ & 79.1 & 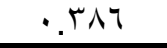 & الزهور & $1 \varepsilon$ \\
\hline or & $1 Y \Sigma .7$ & $1 V .1$ &.$Y M r$ & الرشيد & 10 \\
\hline $1 \% \cdot \pi$ & $r \wedge) \leq . V$ & $\left.\varepsilon \cdot Y_{.}\right)$ & . . . & الأقسام البلدية كافة & 17 \\
\hline
\end{tabular}

Source: Obey M. Al-Wattar, 2006, "Population, Residential Solid Waste Generation and Contieners Need in Mousl City", Journal of Solid Waste Technology's Management, Vol. 32, No. 2, May, P.96.

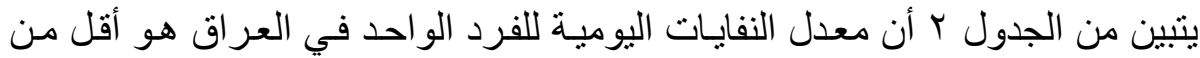

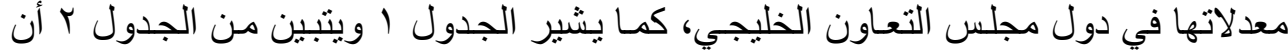

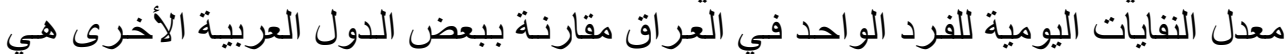

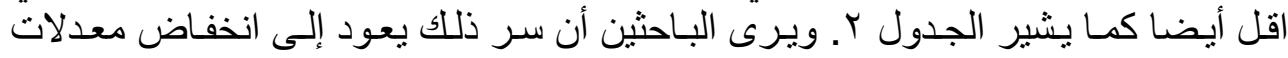

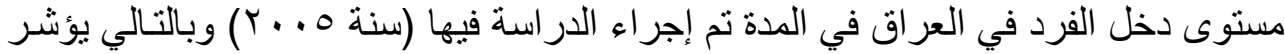
انخفاض مستوى الاستهلاك للفرد العر اقي و الذي يؤثر بدوره لعلى كمية النفايات المنتجة. 
[1900] [محمد والجواري

\section{الجدول r الجن}

معدلات توليد المخلفات السكنية الصلبة وحاجة اثثي عشر حياً سكنياً من الحاويات

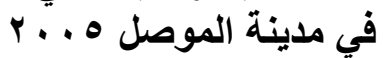

\begin{tabular}{|c|c|c|c|c|c|c|c|}
\hline \multirow[b]{2}{*}{ المجموع } & \multicolumn{3}{|c|}{ عدد الحاويات اللازمة } & \multirow{2}{*}{ 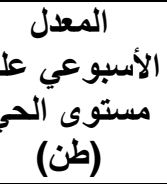 } & \multirow{2}{*}{ للفرد اليومي (كغد) } & \multirow[b]{2}{*}{ القسم البلاي } & \multirow[b]{2}{*}{ ت } \\
\hline & سنة & طنين & ونة & & & & \\
\hline 9 & 1 & $r$ & 0 & 11.7 & . & الأندلس & 1 \\
\hline 1. & 1 & $r$ & 7 & $1 \varepsilon .1$ & .00 & الضباط & $r$ \\
\hline 17 & $r$ & 0 & 9 & YI. $\Lambda$ & .10 & الإصلاح الزراعي & $r$ \\
\hline YI & $\varepsilon$ & 7 & 11 & ro.r & .10 & النهروان & $\varepsilon$ \\
\hline YI & $\varepsilon$ & 7 & 11 & TE. & .10 & الرشيدية & 0 \\
\hline T & 7 & $\Lambda$ & IV & or. & . & الز هر اء & 7 \\
\hline ro & $r$ & $\mathrm{~V}$ & 10 & To. &. YO. & السكر & $\bar{v}$ \\
\hline ro & 7 & 1 . & 19 & $7 \cdot . r$ & . & سومر & $\bar{\Lambda}$ \\
\hline$r \varepsilon$ & $\varepsilon$ & 1 . & rq & $\varepsilon 9 . \wedge$ & . & التحرير & 9 \\
\hline r. & $r$ & 7 & IT & rA. $\varepsilon$ & . & تل الرمان & 1. \\
\hline YI & $r$ & 7 & 14 & $r \cdot .9$ & . & التأميم & 11 \\
\hline 10 & $T$ & 0 & 9 & YI. & . & اليرموك & $\overline{M T}$ \\
\hline YOA & T & Vo & $1 \leqslant V$ & rqo.V & $. Y T \leq$ & جميع الأحياء أعلاه & 14 \\
\hline
\end{tabular}

Source: Obey M. Al-Wattar, 2006, "Population, Residential Solid Waste Generation and Contieners Need in Mousl City", Journal of Solid Waste Technology's Management, Vol. 32, No. 2, May, P. 96.

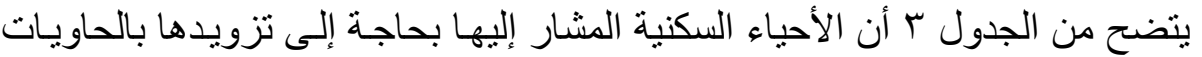

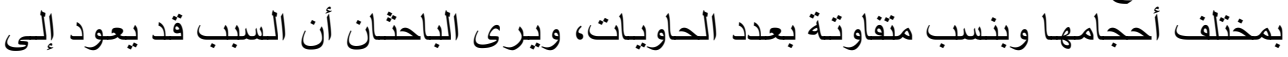
الاختلافات في مساحات المنطقة الجغر افية للأحياء السكنية.

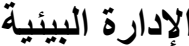

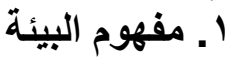

البيئة في اللغة اسم مشتق من الفعل الماضي "باء" "وبو أ" ومضار عها "ييوءء" وتشير

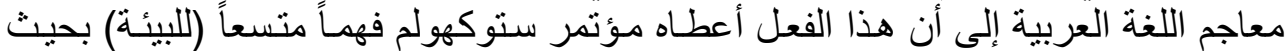

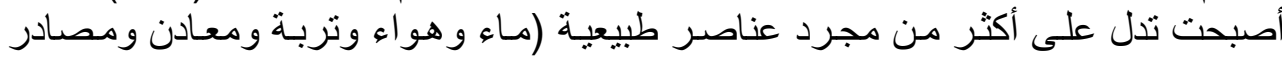

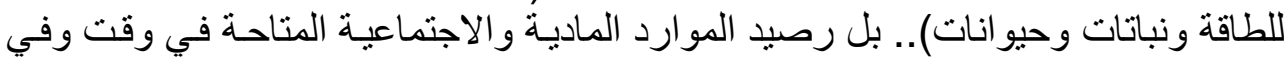

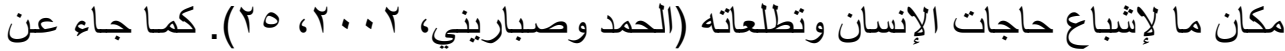

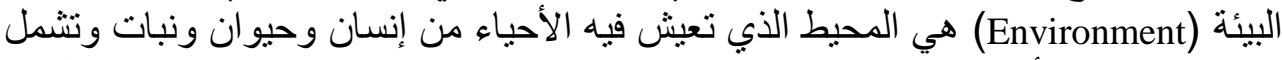

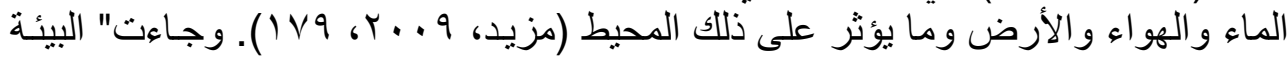

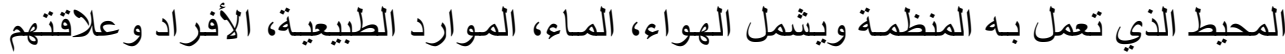


r ـ مفهوم الإدارة البيئية

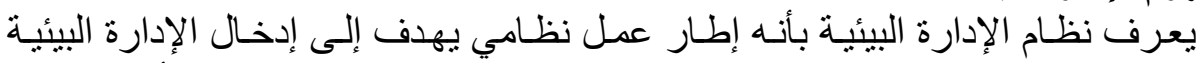

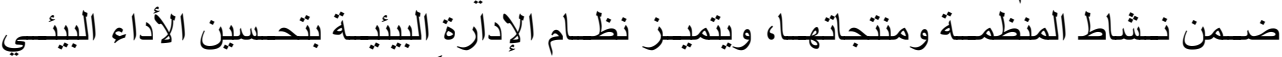

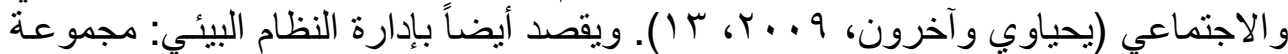

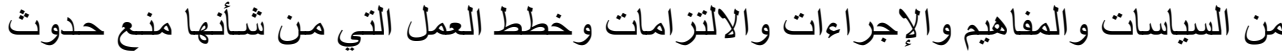

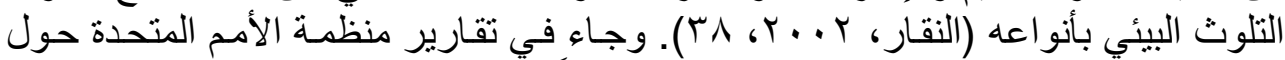

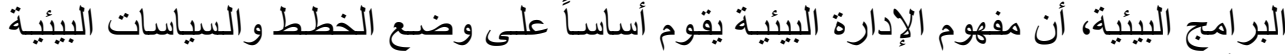

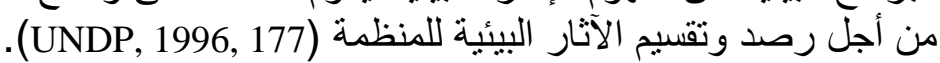
r. مكونات الإدارة البيئية

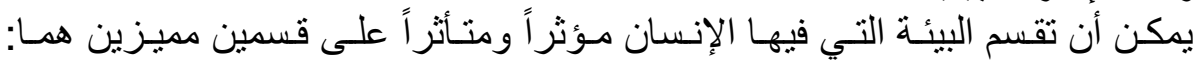

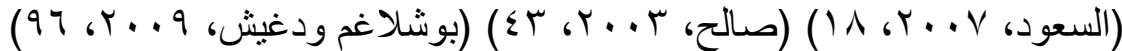
أ. البيئة الطبيعية Natural Environment

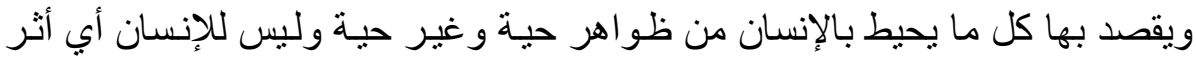

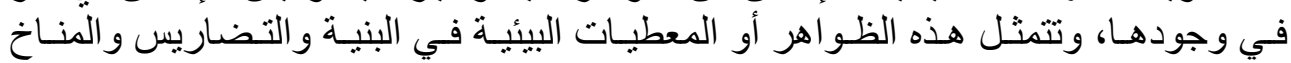
و التربة و النباتات و والحيو انتات.

\section{ب. بالبيئة البشرية Human Environment}

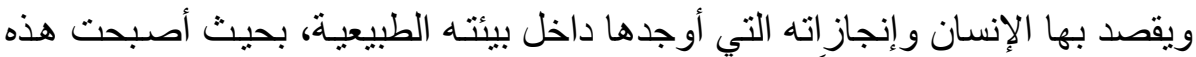

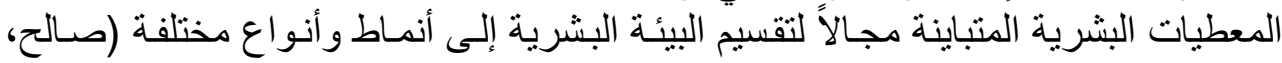

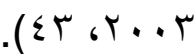

Social Environment ت. البيئة الاجتماعية

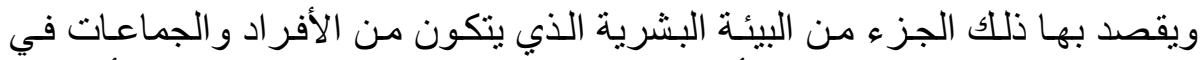

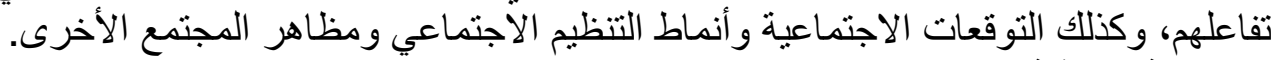
Cultural Environment ث. البيئة الثقافية

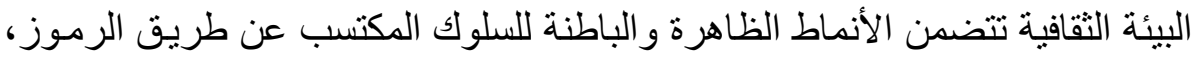

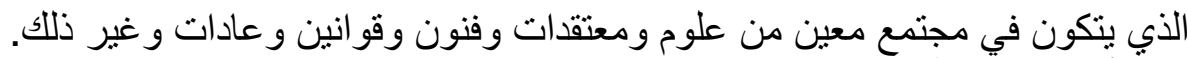
أ. الأهداف البيئية على مستوى الأبية الدولة

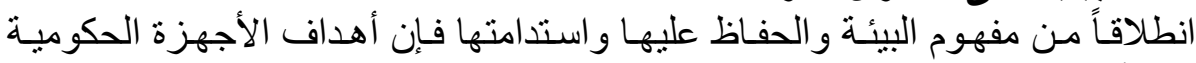

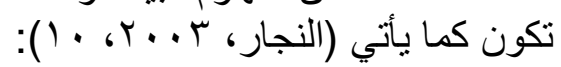

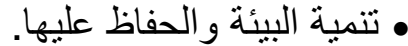

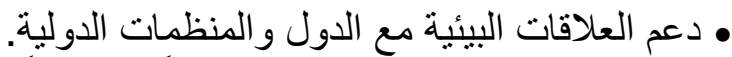

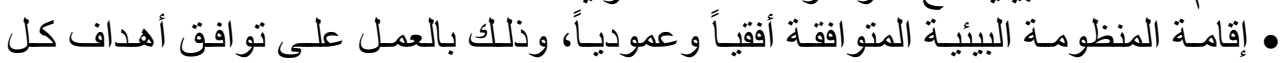

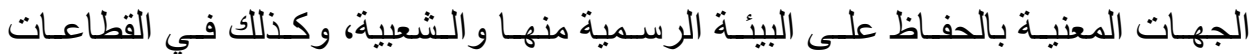
الإنتاجية المختلفة.

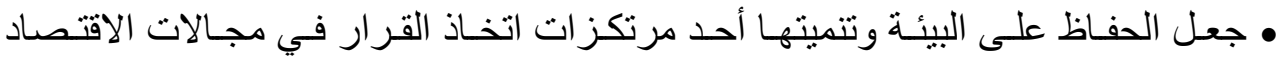

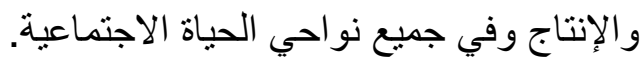

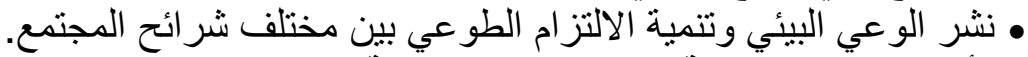
ب. أهداف الإدارة البيئية على مستوى المنظمة الإلئ 
أكد (Draker) على أن الأهداف في مجال منظمات الأعمال تمكن الإدارة من التحليل

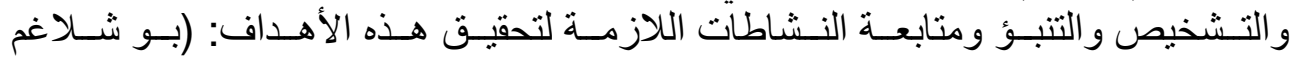

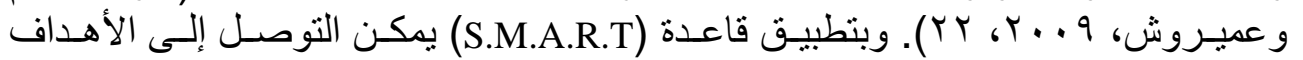

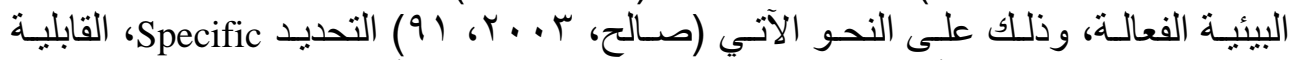

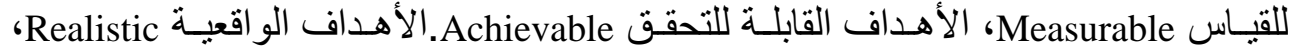
الأهداف البيئية في إطار زمني Time-Bound.

هـ التشريعات البيئية

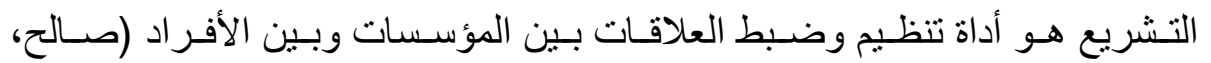

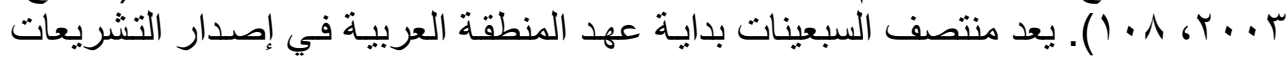

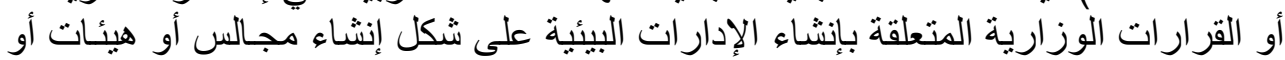

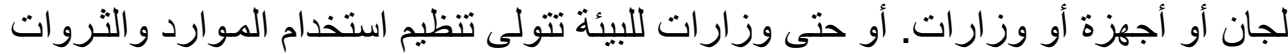

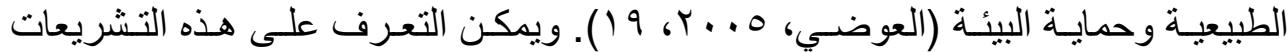

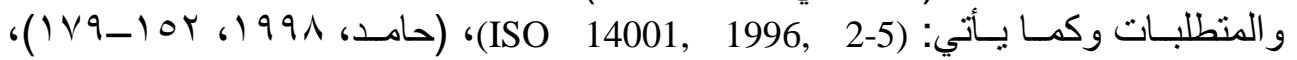

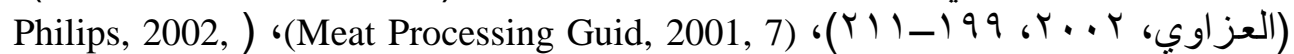
(Ved, 1998, 1) ،(Harring Tons and Knight, 1999, 16-108) ،28-29 ا. المتطلبـات العامـة General Requirements. ؟. السياسة البيئية Environment Policy. r. التخطيط Planning. ع. التنفيذ والتشغيل Implementation and Operation. والإجراء التصحيحي Checking and Corrective Action.

ثالثاًاستراتيجيات الإدارة البيئية الآمنة للنفايات الصلبة

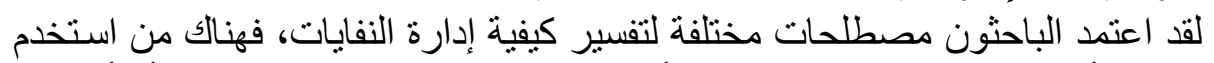

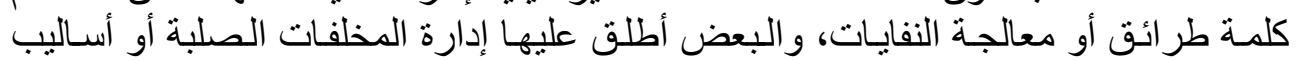

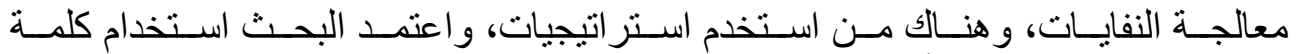

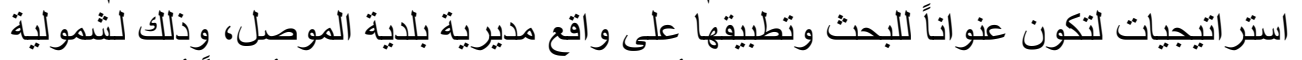

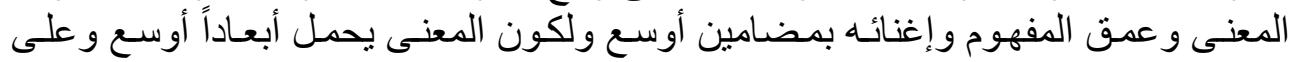
وقد أثنـار (محمود) إلى عدد من الاستر اتيجيات التي تعد الحل الأمثل لحل مشكلة

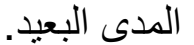

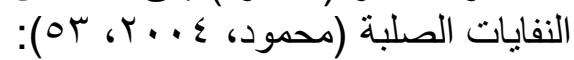
ا. الحد من إنتاج النفايات بإتباع طر ائق سـهلة، وتعتمد هذه الطريقة على رفع مستوى

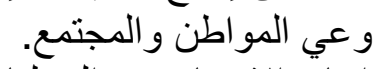

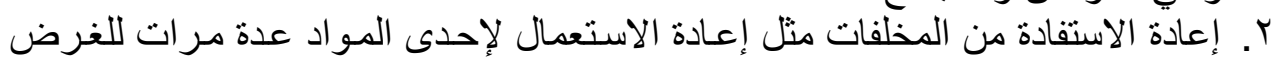

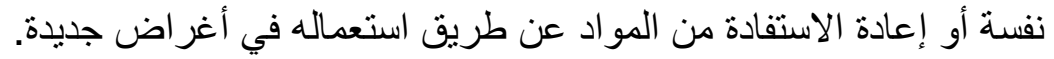

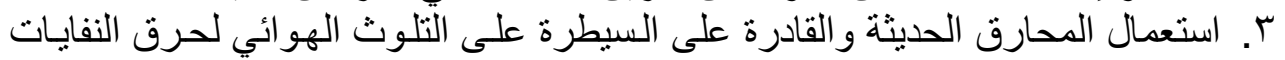
الو اجب حرقها.

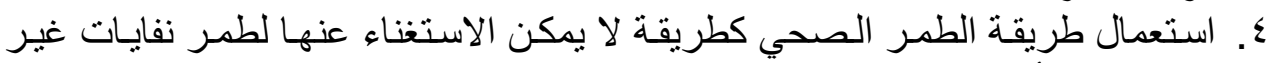

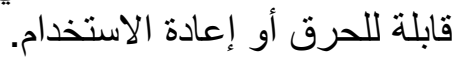

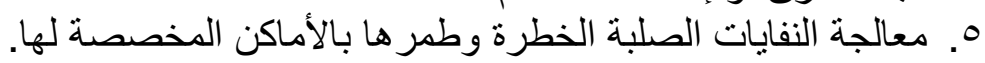

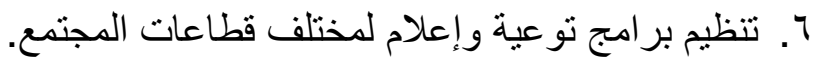




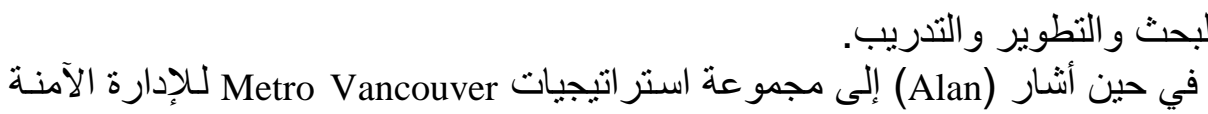

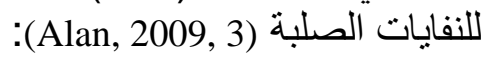

ا. الإستراتيجية الأولى: تصفير النفايـات: أبي دعم أخلاقيـات تصفير النفايـات من خـلال

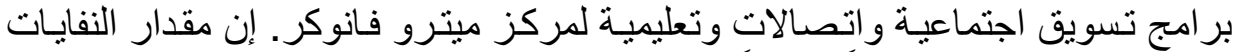

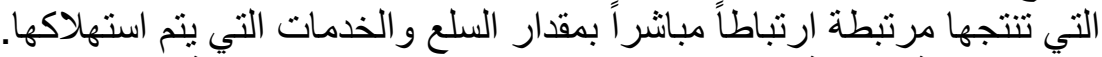

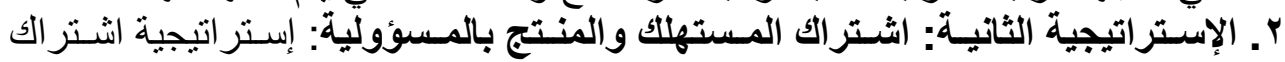

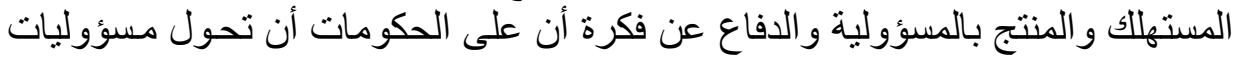

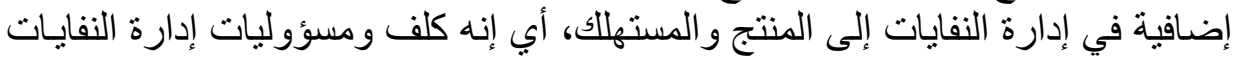

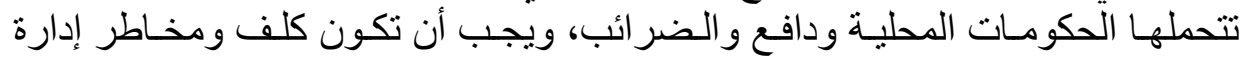

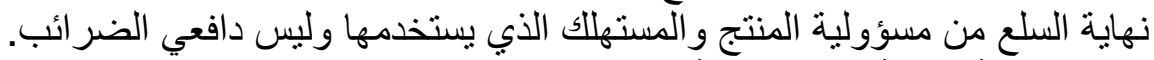

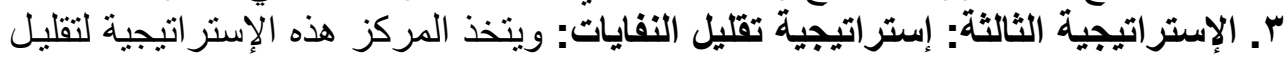

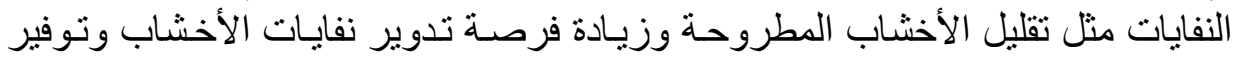

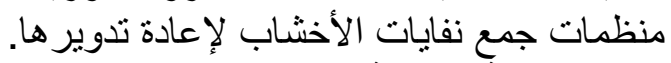

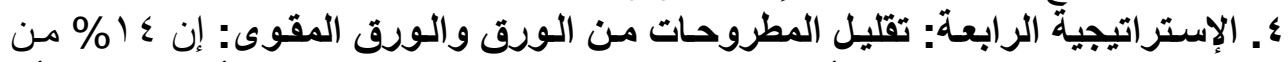

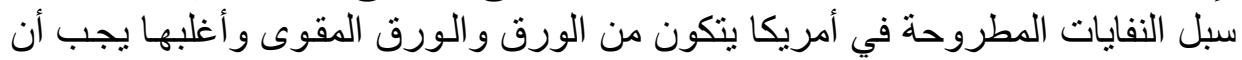

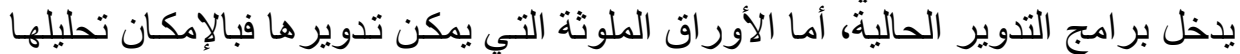

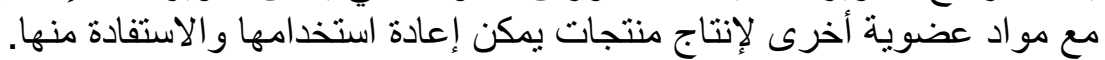

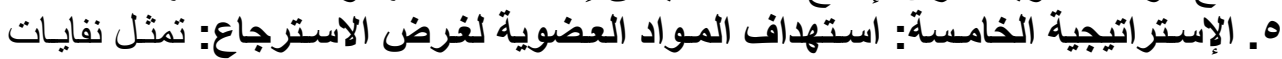

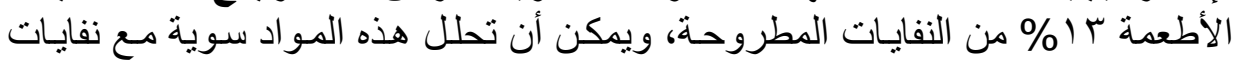
الحدائق والباحات وبعض الإهن الورق المقوى ينتج منها منتجات مفيدة وقابلة للتسويق.

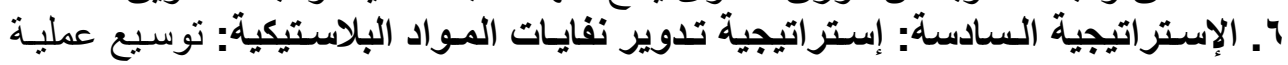

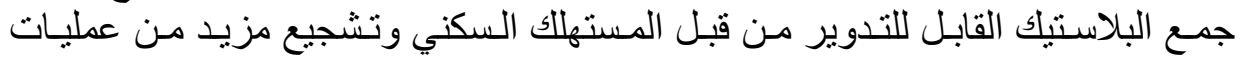

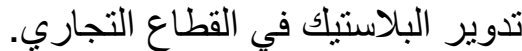

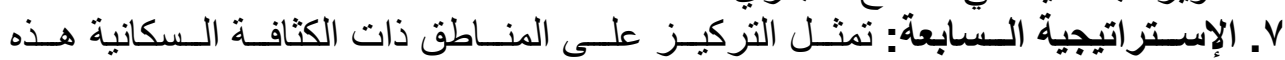

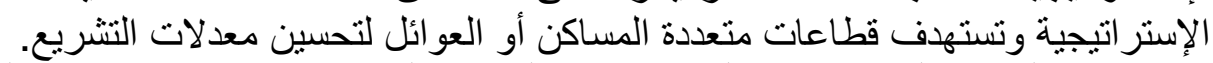

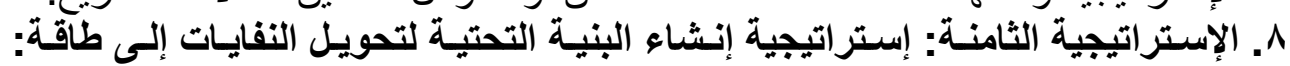

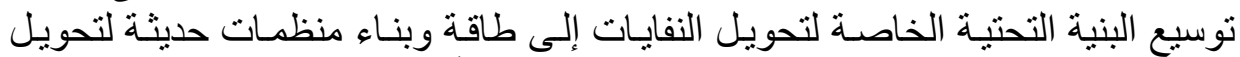

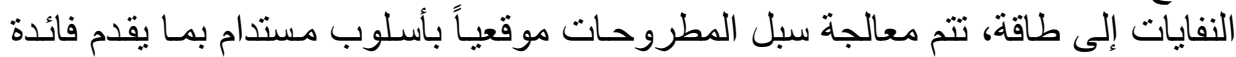
على شكل طاقة وحر ارة للمنطقة الإنة 9. الإستراتيجية التاسعة: إستراتيجية تطوير نظام التدوير لنفايـات المعادن: تطوير نظام

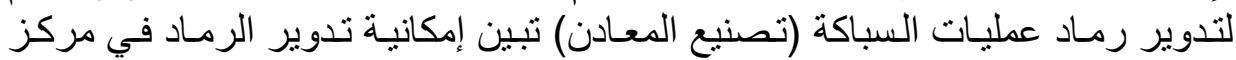

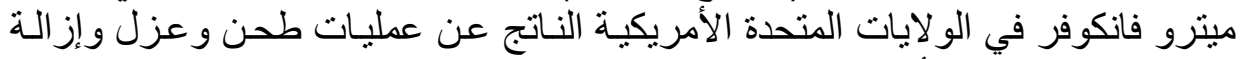

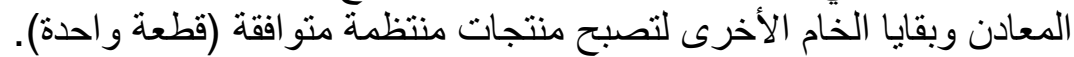
• 1 ـ الإستراتيجية العاشرة: طرح الفضلات المتبقية وتقليل التأثير البيئي إلى الحد الألى التهى:

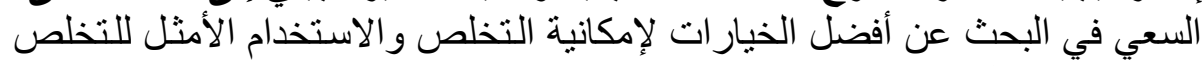
من الفضلات المعالجة التي لم يعد هناك فائدة منها. 


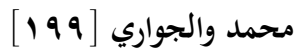

عرض نتائج الاراسة وتحليلها

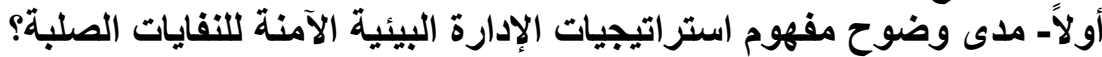

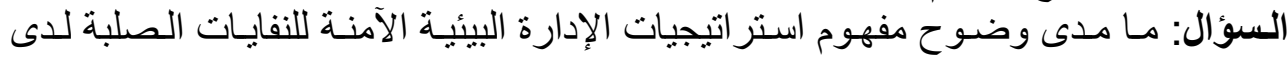

عينة الدر اسةٌ و هل لايها رؤية و اضحة بشأنها؟

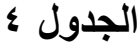

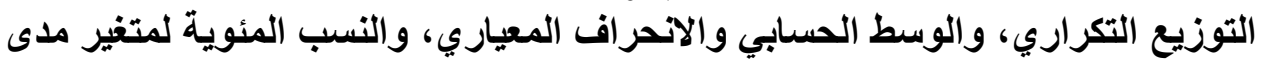

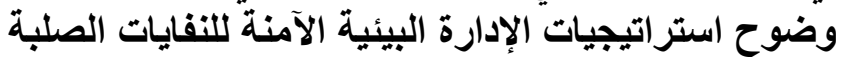

\begin{tabular}{|c|c|c|c|c|c|c|c|c|}
\hline \multirow{2}{*}{ المعياري } & \multirow{2}{*}{ الوسط الحسابي } & \multicolumn{2}{|c|}{ غير واضح } & \multicolumn{2}{|c|}{ واضح إلى حد ما } & \multicolumn{2}{|c|}{ واضح } & \multirow{2}{*}{ المتغير } \\
\hline & & $\%$ & التكرار & $\%$ & التكرار & $\%$ & التكرار & \\
\hline •. & 1.09 & $09.4 \lambda$ & 19 & $r I . \wedge \Lambda$ & V & $11 . v_{0}$ & 7 & $\mathrm{X}_{1}$ \\
\hline. .17 & $\therefore \varepsilon$ & $1 \leq . \wedge \varepsilon$ & & $0 . \Sigma V$ & & $\varepsilon .79$ & & الكلئشر \\
\hline
\end{tabular}

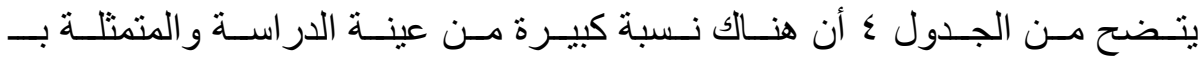

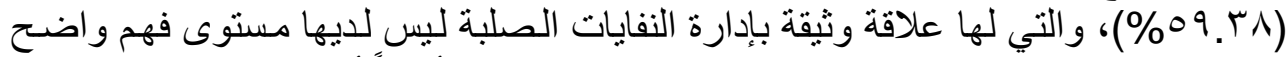

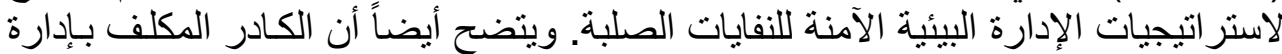

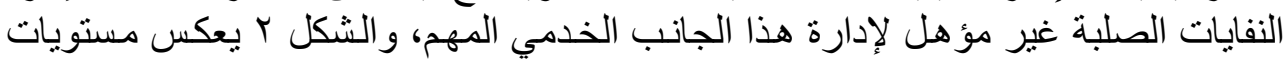

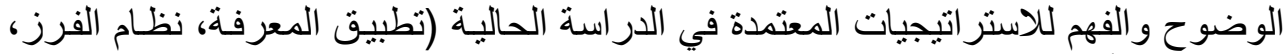

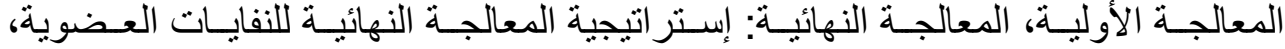

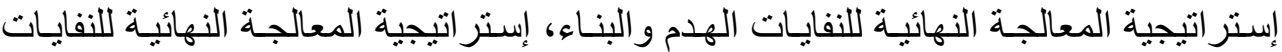

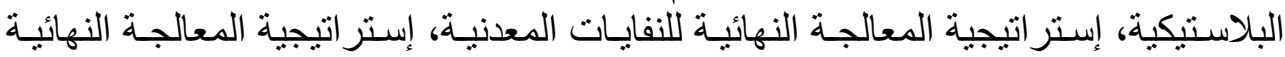

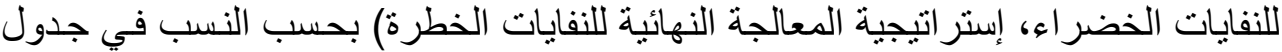
التحليل للسؤال عن مدى وضوح استر اتيجيات الإدارة البيئية الآمنة للنفايات الصلبة.

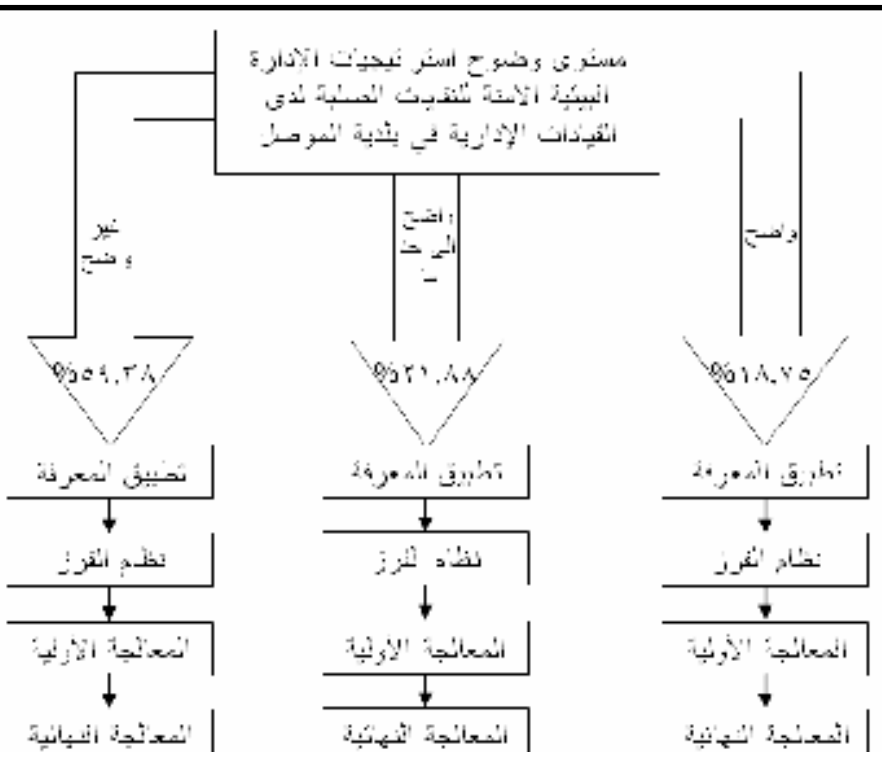




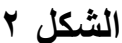

نسب الوضوح لاستراتيجيات الإدارة البيئية الآمنة في النفايات الصلبة

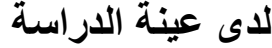

الثكل من إعداد الباحثنان

ثاتياً. تحليل نتائج إستراتيجية الإدارة البيئية الآمنة للنفايات الصلبة

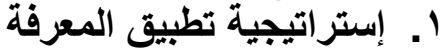

\begin{tabular}{|c|c|c|c|c|c|c|c|c|}
\hline \multicolumn{9}{|c|}{ لتوزيع التكراري، والوسط الحسابي والانحراف المعياري، والتسب المئويـة لمتغير تطبيق } \\
\hline \multirow{2}{*}{ الاتحراف المعياري } & \multirow{2}{*}{ الحسابي } & \multicolumn{2}{|c|}{ لا أتفق } & \multicolumn{2}{|c|}{ محايد } & \multicolumn{2}{|c|}{ أتفق } & \multirow{2}{*}{ المتغير } \\
\hline & & $\%$ & التكرار & $\%$ & التكرار & $\%$ & التكرار & \\
\hline.$V$ & $1 . \leqslant \varepsilon$ & VA. Ir & ro & صفر & صفر & 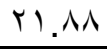 & V & $X_{1}$ \\
\hline .7 . & 1.10 & 07.10 & 11 & Ir.o. & $\varepsilon$ & ס. ו & 1. & $\mathrm{X}_{2}$ \\
\hline.$\wedge 0$ & 1.11 & 94.80 & r. & صفر & صفر & 7.10 & $r$ & $X_{3}$ \\
\hline .79 & $1 . \leqslant V$ & $\vee \backslash . \wedge \wedge$ & $T r$ & $9 . \mu \wedge$ & $r$ & 11.10 & 7 & $\mathrm{X}_{4}$ \\
\hline$\because \wedge$. & $I . Y Y$ & $\Lambda V .0$. & $r \wedge$ & $r .1 r$ & $T$ & $9 . \Gamma \wedge$ & $r$ & $\mathrm{X}_{5}$ \\
\hline$\because V \mu$ & $1 . \varepsilon$. & $V \vee .0$. & & $0 .$. & & $1 V .0$. & & المؤشر \\
\hline
\end{tabular}

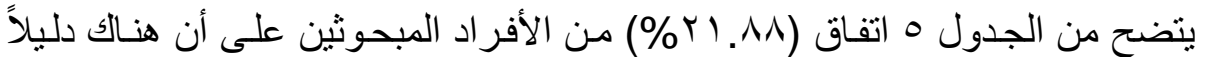

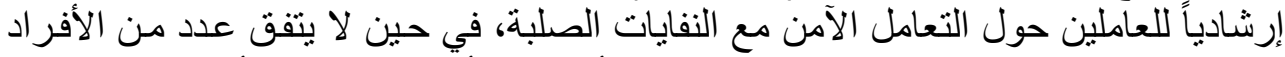

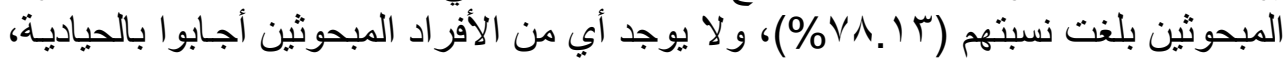

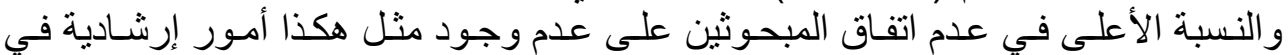

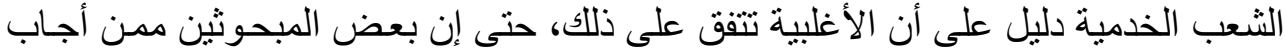

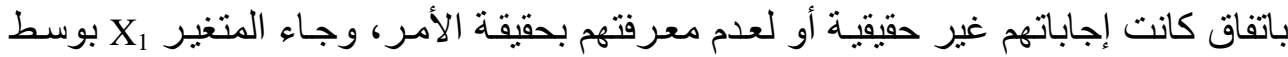

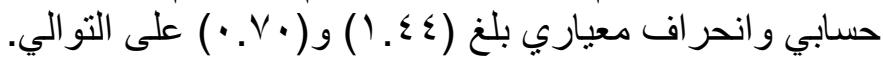




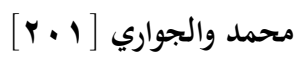

ثانياً - إستراتيجية نظام الفرز

\begin{tabular}{|c|c|c|c|c|c|c|c|c|}
\hline \multicolumn{9}{|c|}{ الجدول 7} \\
\hline \multirow{2}{*}{ الانحرافياري } & \multirow{2}{*}{ الحسابي } & \multicolumn{2}{|c|}{ لا أتفق } & \multicolumn{2}{|c|}{ محايد } & \multicolumn{2}{|c|}{ أتفق } & \multirow{2}{*}{ المتغير } \\
\hline & & $\%$ & التكرار & $\%$ & التكرار & $\%$ & التكرار & \\
\hline.$\wedge \Gamma$ & 1.17 & $9 . .74$ & rq & $r .1 T$ & 1 & 7.10 & r & $X_{1}$ \\
\hline$\because \vee \wedge$ & 1.10 & AV.O. & rA & صفر & صفر & $1 T .0$. & $\varepsilon$ & $\mathrm{X}_{2}$ \\
\hline.$V T$ & $1 . \mathrm{r}$ & VA. IT & ro & $7 . r_{0}$ & r & 10.7 & 0 & $\mathrm{X}_{3}$ \\
\hline.$V \varepsilon$ & 5.74 & 1r.o. & $\varepsilon$ & $9.4 \wedge$ & $r$ & VA. IT & ro & $\mathrm{X}_{4}$ \\
\hline $.7 \varepsilon$ & $1.7 \pi$ & 71.10 & Tr & صفر & صفر & T. T. & 1. & $\mathrm{X}_{5}$ \\
\hline.$V \varepsilon$ & 1.71 & $7 V .0$. & & r.vo & & rᄉ.Vo & & المؤشر الكلي \\
\hline
\end{tabular}

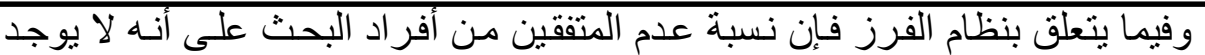

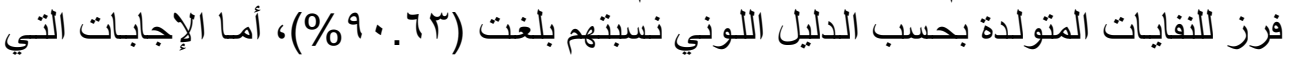

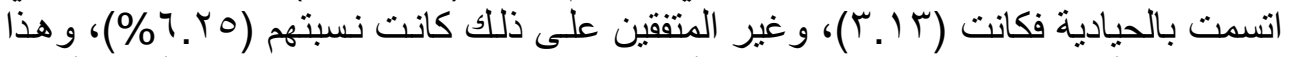

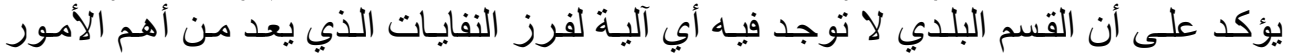

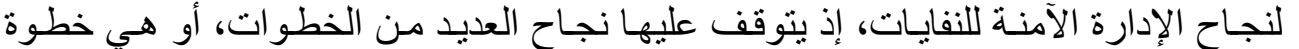

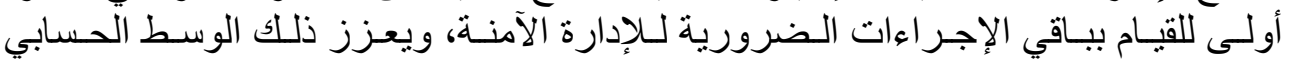

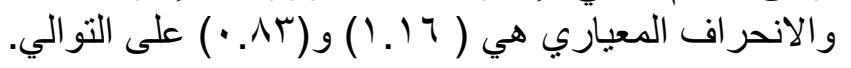

ثالثاً. إستراتيجية المعالجة الأولية

\begin{tabular}{|c|c|c|c|c|c|c|c|c|}
\hline عالة الأولية & لمتغير & ب المئو & ب، وال & دول المعب V & والاند & طا الحسد & والو & وزيع التكرا \\
\hline الانحراف & الوسط & & & & & ق & & المتفـ \\
\hline المعياري & الحسابي & $\%$ & التكرار & $\%$ & التكرار & $\%$ & التكرار & الفضيز \\
\hline.$V \varepsilon$ & $1 . r \varepsilon$ & NI.Yo & $r 7$ & $r .1 T$ & 1 & 10.74 & 0 & $\mathrm{X}_{1}$ \\
\hline.$\wedge \wedge$ & T. $9 \varepsilon$ & $r .14$ & 1 & صفر & صفر & $97 . \wedge 1$ & $r$ & $\mathrm{X}_{2}$ \\
\hline$\cdot v 1$ & $1 . \leqslant 1$ & vo... & $r \varepsilon$ & $9 . r \wedge$ & $r$ & $10.7 \pi$ & 0 & $\mathrm{X}_{3}$ \\
\hline .120 & 5.79 & 10.74 & 0 & صفر & صفر & $\Lambda \varepsilon . \Gamma \wedge$ & TV & $\mathrm{X}_{4}$ \\
\hline.$\wedge$. & r.VA & 9.41 & $r$ & $r .1 T$ & 1 & NV.O. & rA & $\mathrm{X}_{5}$ \\
\hline.$\vee \wedge$ & T.YT & r. & & $r .1 r$ & & $7 . \ldots$ & & المؤشر الكلي \\
\hline
\end{tabular}

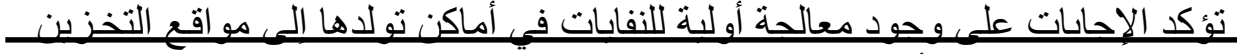

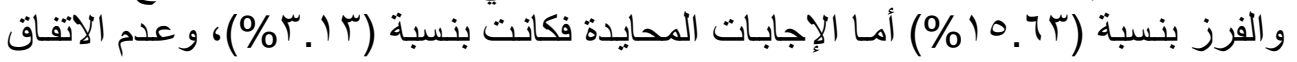

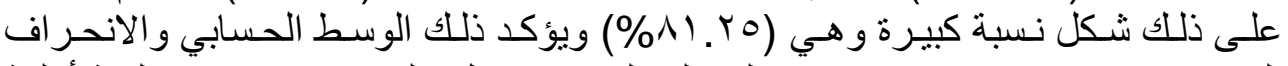

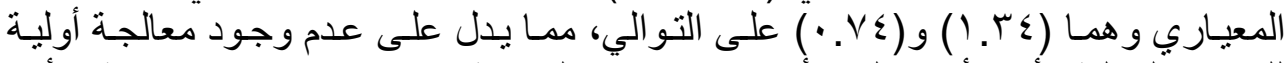

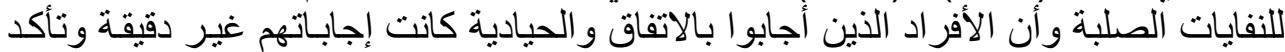

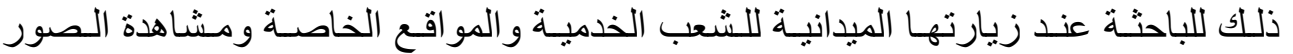


الخاصة بالنفايات الصلبة. تشير الإجابات الخاصة بالمتغير X2 باتفاق نسبة كبيرة من أفر اد

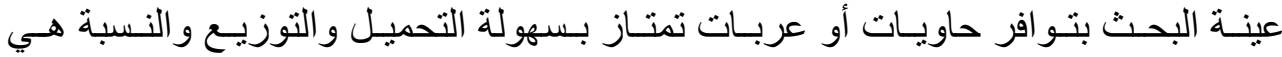

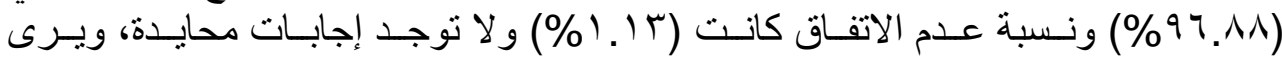

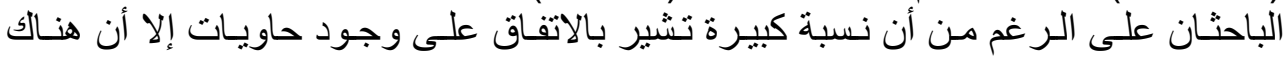

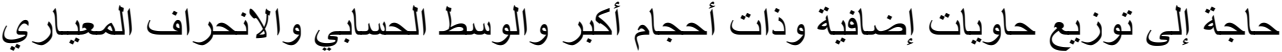

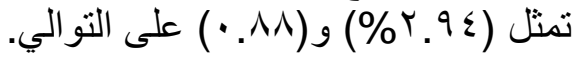

رابعاً. إستراتيجية المعالجة النهائية للنفايات العضوية

\section{الجدول}

التوزيع التكراري، والوسط الحسابي والانحراف المعياري، والنسب المئوية

لمتغير النفايات العضوية

\begin{tabular}{|c|c|c|c|c|c|c|c|c|}
\hline \multirow{2}{*}{ الالمعرافي } & \multirow{2}{*}{ الحسبابي } & \multicolumn{2}{|c|}{ لا أتفق } & \multicolumn{2}{|c|}{ محايد } & \multicolumn{2}{|c|}{ أتفق } & \multirow{2}{*}{ المتغير } \\
\hline & & $\%$ & التكرار & $\%$ & التكر ار & $\%$ & التكرار & \\
\hline$\cdot{ }^{\wedge} 1$ & 1.19 & $\Lambda V .0$. & $r \wedge$ & 7.10 & $r$ & 7.10 & $r$ & $\mathrm{X}_{1}$ \\
\hline$\because V \varepsilon$ & $1 . r \varepsilon$ & 11. Yo & ru & $r .1 T$ & 1 & 10.71 & 0 & $X_{2}$ \\
\hline.$\wedge 7$ & 1.99 & $94 . \vee 0$ & r. & r. & 1 & r. & 1 & $\mathrm{X}_{3}$ \\
\hline$\cdot \wedge 1$ & $1 . Y$ & AV.O. & & $\varepsilon .1 \mathrm{~V}$ & & א. 1. & & المؤشي الكي \\
\hline
\end{tabular}

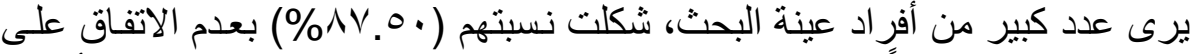

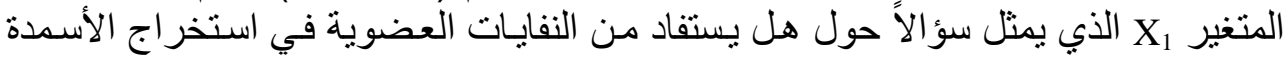

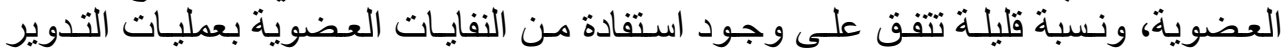

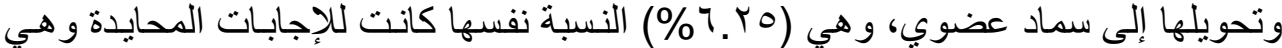

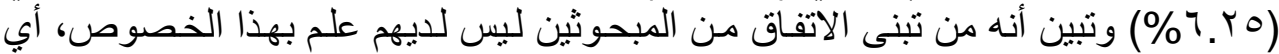

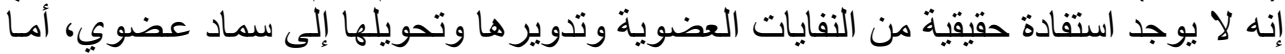

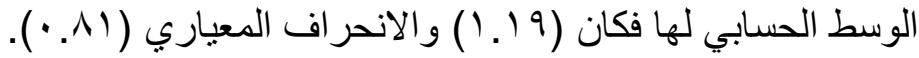

خامساً- إستراتيجية المعالجة النهائية لنفايات الههم والبناء

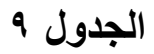

التوزيع التكراري، والوسط الحسابي والاتحراف المعياري، والنسب المئوية

لمتغيز نفايات الهدم والبناء

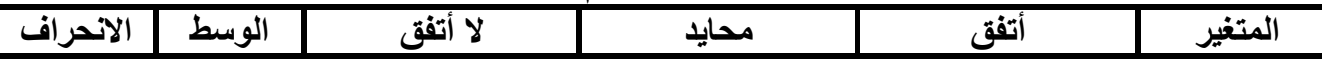




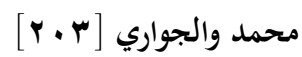

\begin{tabular}{|c|c|c|c|c|c|c|c|c|}
\hline المعياري & الحسابي & $\%$ & التكرار & $\%$ & التكرار & $\%$ & التكرار & \\
\hline .10 & 1.11 & $9 . .17$ & $r q$ & 7.10 & $r$ & $5.1 T$ & 1 & $X_{1}$ \\
\hline .10 & 1.11 & 94.80 & $\mu$. & صفر & صفر & 7.10 & $r$ & $\overline{X_{2}}$ \\
\hline .10 & 1.1. & 94.19 & & r. & & $\varepsilon .79$ & & المؤشير \\
\hline
\end{tabular}

كما يشير الجدول 9 الخـاص بالمعالجة النهائية لنفايات الهدم و البنـاء إلى التوزيعات التهات

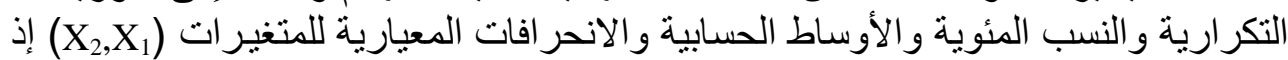

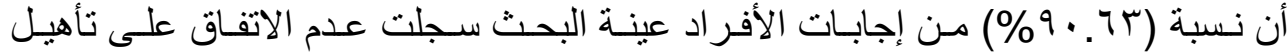

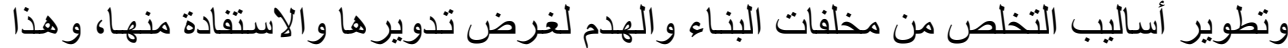

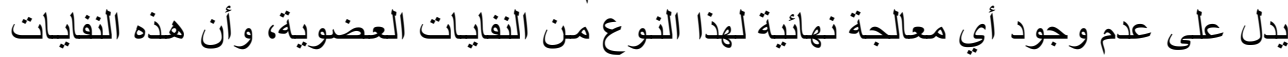

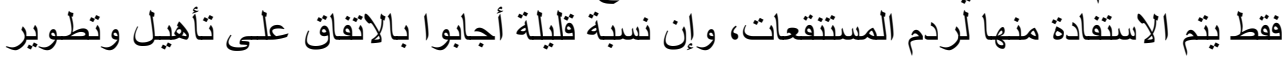

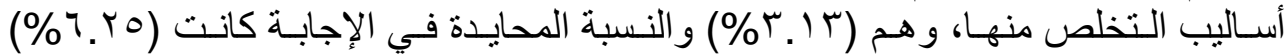

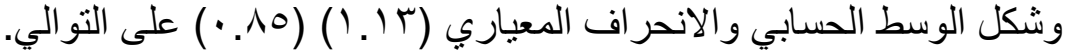

سادساً- استراتيجية المعالجة النهائية للنفايات البلاستيكية

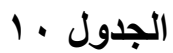

التوزيع التكراري، والوسط الحسابي والانحراف المعياري، والنسب النئئية المئوية لمتغير النفايّات البلاستيكية

\begin{tabular}{|c|c|c|c|c|c|c|c|c|}
\hline \multirow{2}{*}{ الالمعرافي } & \multirow{2}{*}{ الحسابي } & \multicolumn{2}{|c|}{ لا أتققى } & \multicolumn{2}{|c|}{ محايد } & \multicolumn{2}{|c|}{ أتقق } & \multirow{2}{*}{ المتغير } \\
\hline & & $\%$ & التكرار & $\%$ & التكرار & $\%$ & التكرار & \\
\hline$\because V Y$ & 1.19 & Vo.VT & ro & 9.9 & $r$ & 10.10 & 0 & $\mathrm{X}_{1}$ \\
\hline..$\vee \wedge$ & $1 . r 0$ & $\Lambda \varepsilon . \mu \wedge$ & rV & 7.10 & $r$ & $q . \mu$ & $r$ & $\mathrm{X}_{2}$ \\
\hline$\because$ Vo & I.r & $\Lambda \cdot . v$ & & $V .7 V$ & & דצ.r & & الكوئشي \\
\hline
\end{tabular}

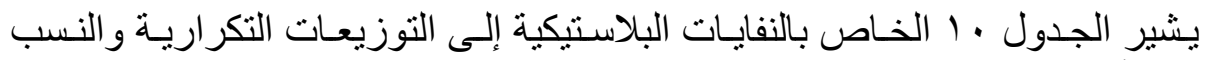
المئويـة والأوسـاط الحسابية و الانحر افـات المعياريـة للمتغيرين (X,

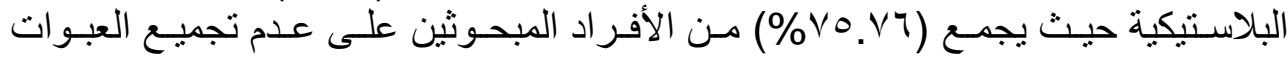

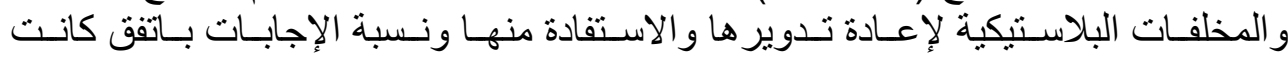

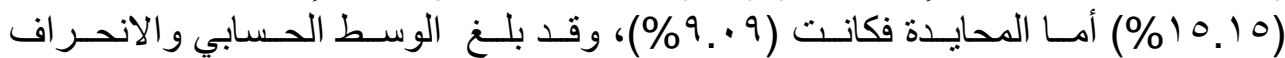

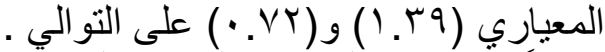
سابعاً إستراتيجية المعالجة النهائية للنفايات المعدنية

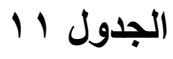

التوزيع التكراري، والوسط الحسابي والاتحراف المعياري، والنسب المئوية

\section{لمتغير النفايات المعدنية}

المتفير




\begin{tabular}{|c|c|c|c|c|c|c|c|c|}
\hline المعياري & الحسابي & $\%$ & التكرار & $\%$ & التكرار & $\%$ & التكرار & \\
\hline$\cdot . \wedge r$ & 1.17 & $9 \cdot .74$ & $r q$ & $r .14$ & 1 & 7.10 & $r$ & $X_{1}$ \\
\hline.$\wedge 1$ & 1.19 & $9 \cdot .74$ & rq & صفر & صفر & $9 . \mu \wedge$ & $r$ & $\overline{X_{2}}$ \\
\hline.$\wedge r$ & $1.1 \mathrm{~V}$ & $9.7 \pi$ & & 1.07 & & $V . \Lambda I$ & & المؤشير \\
\hline
\end{tabular}

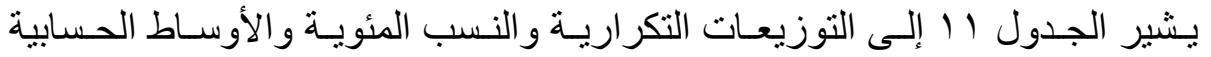

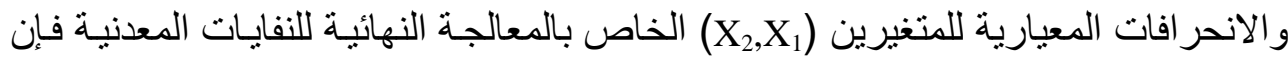

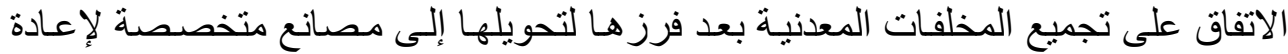

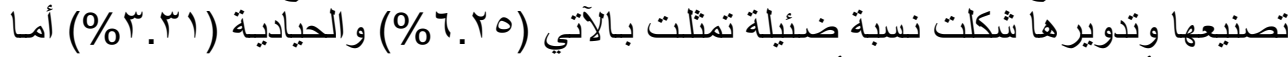

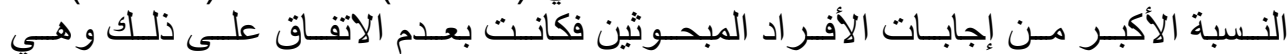

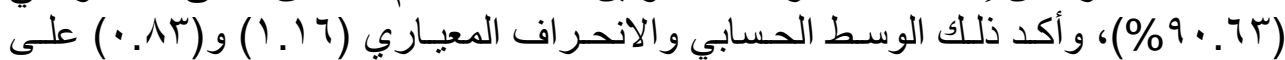

ثامناً إستراتيجية المعالجة النهائية للنفايات الخضر اء

\begin{tabular}{|c|c|c|c|c|c|c|c|c|}
\hline & ب المئ & ي، وا & ضر اءع الم & 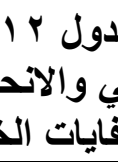 & لمتغير الحس & ي ي، والو & ع التك & \\
\hline \multirow{2}{*}{ المعياري } & \multirow{2}{*}{ الحسابي } & \multicolumn{2}{|c|}{ لا أتفق } & \multicolumn{2}{|c|}{ محايد } & \multicolumn{2}{|c|}{ أتفق } & \multirow{2}{*}{ المتغير } \\
\hline & & $\%$ & التكرار & $\%$ & التكرار & $\%$ & التكرار & \\
\hline. $\mathrm{VO}$ & 1.4 & $\Lambda \leqslant . r \Lambda$ & rV & صفر & صفر & 10.74 & 0 & $\mathrm{X}_{1}$ \\
\hline.$V V$ & $1 . Y \Lambda$ & VA. IT & ro & 10.74 & 0 & 7.10 & r & $\mathrm{X}_{2}$ \\
\hline$\because \wedge$. & $1 . r Y$ & NV.O. & rA & $r .1 T$ & 1 & 9.11 & $r$ & $\mathrm{X}_{3}$ \\
\hline$\because V V$ & $1 . r V$ & אז.זהג & & $7 . T_{0}$ & & $1 \cdot . \leqslant r$ & & الكوئشر \\
\hline
\end{tabular}

يشير الجدول با إلـى التوزيعـات التكر اريـة و النسب المئويسة والأوسـاط الحسابية

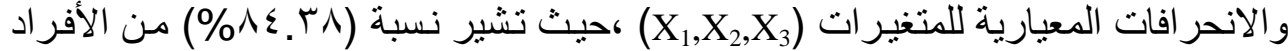

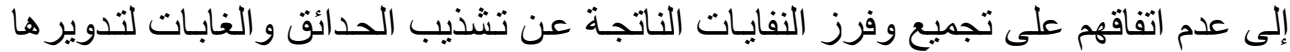

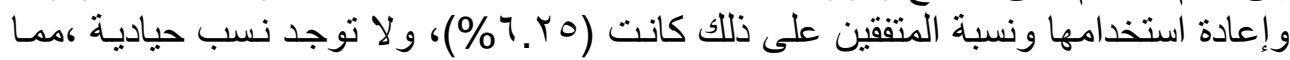

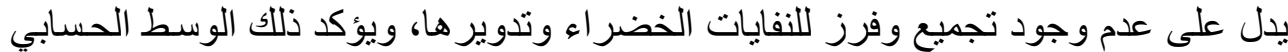

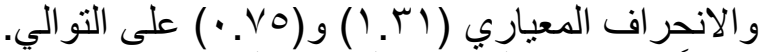
تاسعاً- إستراتيجية المعالجة النهائية للنفايات الخطرة

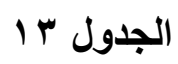

التوزيع التكراري، والوسط الحسابي والاتحراف المعياري، والنسب المئوية لمتغير النفايات الخطرة

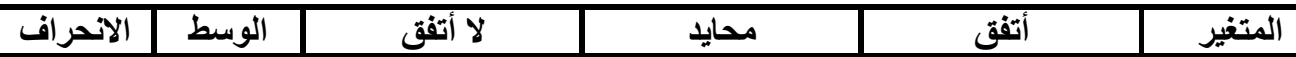




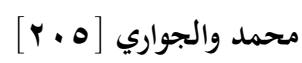

\begin{tabular}{|c|c|c|c|c|c|c|c|c|}
\hline المعياري & الحسابي & $\%$ & التكرار & $\%$ & التكرار & $\%$ & التكرار & \\
\hline$\because \vee \wedge$ & 1.50 & AV. 0. & rA & صفر & صفر & $1 Y .0$. & $\varepsilon$ & $X_{1}$ \\
\hline$\cdot . \wedge \wedge$ & 1.7 & 94.80 & r. & 7.10 & $r$ & صفر & صفر & $\mathrm{X}_{2}$ \\
\hline$\because 9$. & 1.4 & 97.11 & M & r. & 1 & صفز & صفر & $\mathrm{X}_{3}$ \\
\hline .91 & $1 . \cdots$ & $1 \ldots$ & rT & صفر & صفر & صفر & صفر & $\mathrm{X}_{4}$ \\
\hline.$\wedge \mathrm{V}$ & 1.9 & $9 \varepsilon .04$ & & r.rE & & וז.r & & المؤشير \\
\hline
\end{tabular}

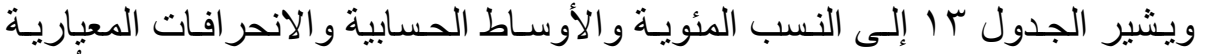

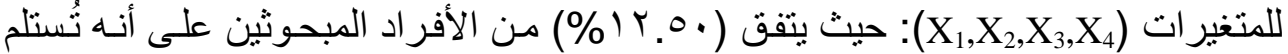

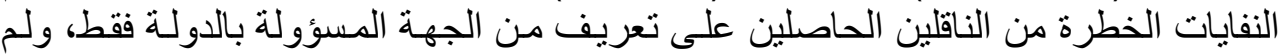

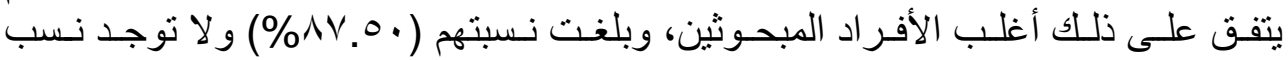

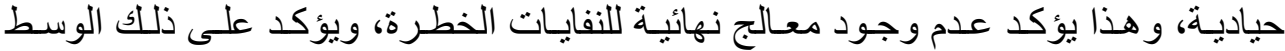

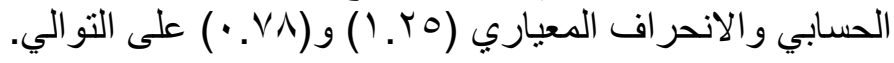

ثالثاً- معوقات تطبيق استراتيجيات الإدارة البيئة الآمنة للنفايات الصلبة

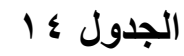

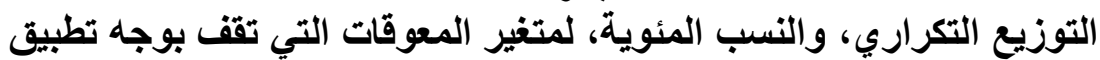
استر اتيجيات الإدارة البيئة الآمنة للنفايات الصنية الصنية

\begin{tabular}{|c|c|c|c|c|c|}
\hline \multirow{3}{*}{ المجموع الكلي } & \multirow{2}{*}{\multicolumn{2}{|c|}{ الإجابة }} & \multirow{2}{*}{\multicolumn{2}{|c|}{ الإجابة }} & \multirow{3}{*}{ المتغير } \\
\hline & & & & & \\
\hline & $\%$ & التكرار & $\%$ & التكرار & \\
\hline rr & 14.0. & $\varepsilon$ & $\Lambda \vee .0$. & $r \wedge$ & $\mathrm{X}_{1}$ \\
\hline$r Y$ & Y!.A1 & $\mathrm{V}$ & $\nabla \wedge .1 T$ & To & $X_{2}$ \\
\hline rr & ro... & $\Lambda$ & vo... & $r \varepsilon$ & $X_{3}$ \\
\hline rY & $9 . r \wedge$ & $r$ & $9 \cdot .74$ & rq & $\mathrm{X}_{4}$ \\
\hline rY & $r .1 T$ & 1 & $97 . \wedge 1$ & 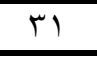 & $X_{5}$ \\
\hline rY & 11.10 & 7 & 11. ro & ry & $\mathrm{X}_{6}$ \\
\hline rr & $r \Lambda .1 T$ & 9 & $\vee 1 . \wedge 1$ & r & $X_{7}$ \\
\hline rY & ro... & $\Lambda$ & vo... & $r \varepsilon$ & $\mathrm{X}_{8}$ \\
\hline
\end{tabular}

السؤال: مـا هـي المعوقـات التـي تقف في وجـه تطبيق استر اتيجيات الإدارة البيئيـة الآمنـة للنفايات الصلبة؛

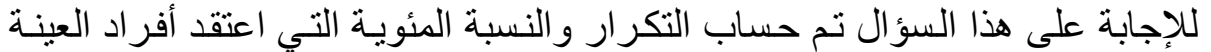

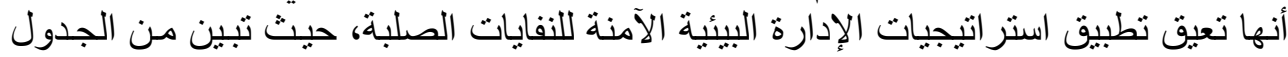

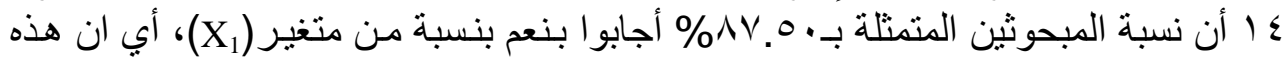

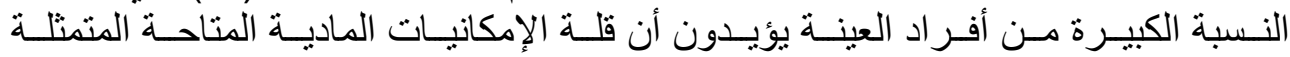


بالتخصيصات لإدارة و إنشاء معامل لمعالجـة النفايـات الصلبة أو إعـادة تدوير ها و الاستفادة

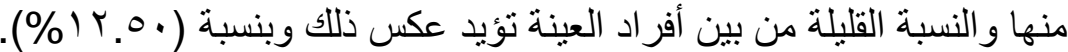

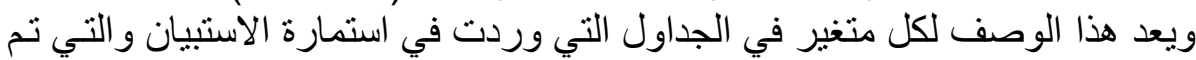

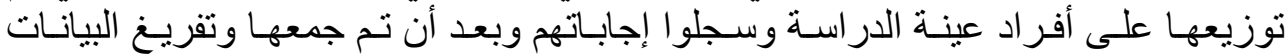
و الحصول على النسب المئوية والمتوسطات الحسابية و الانحر افات المعياريـة يؤكد الباحثنان

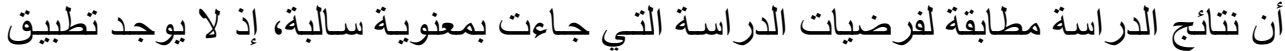

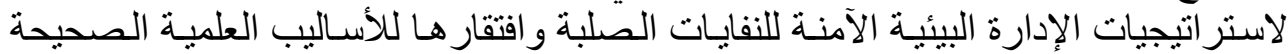

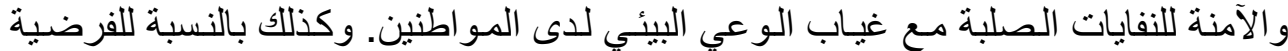

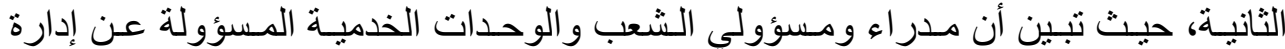

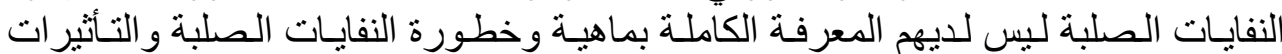

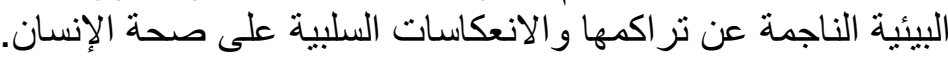

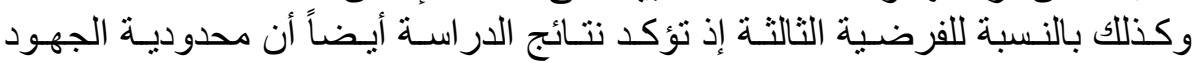

المبذولة من قبل الإدار ات سبب و اضـح في عدم نجاح تطبيق استر اتيجيات الإدارة البيئية

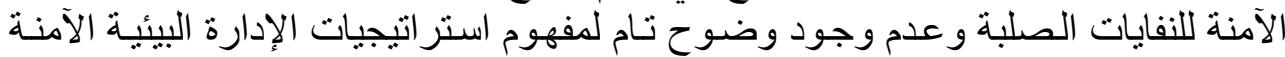

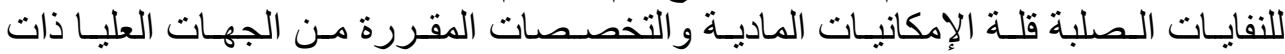
العلاقة.

و أخير اً بالنسبة للفرضية الر ابعة تؤكد نتائج الدر اسة على وجود معوقات إداريـة وفنيـة

ومادية تعيق تطبيق استر اتيجيات الإدارة البيئية الآنية للنفايات الصلية الصلبة.

الاستتتاجات و المقترحات أولاًا - الاستنتاجات واتهات

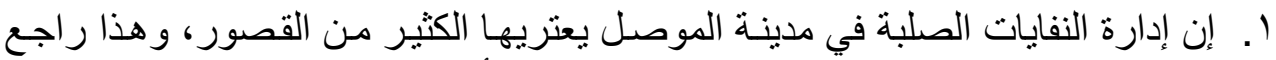

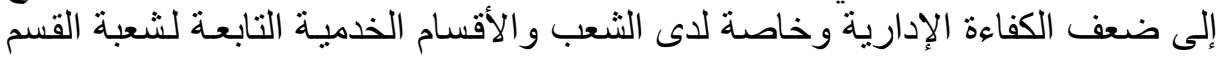

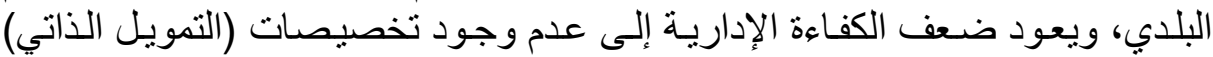

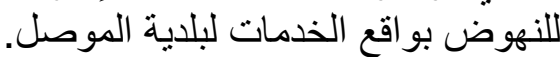

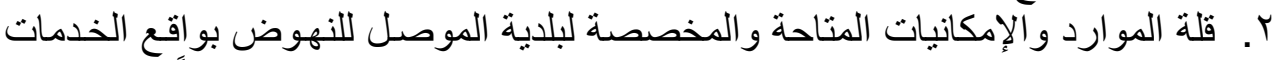

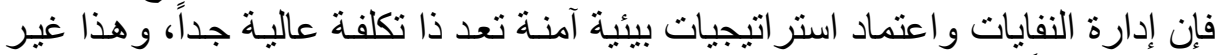

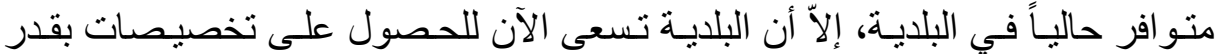

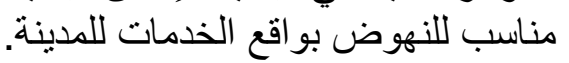

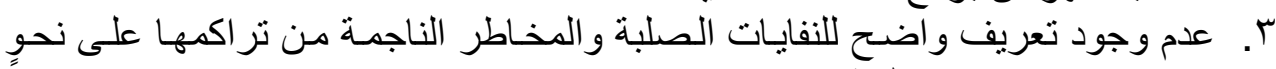
عشو ائي ومن دون معالجة. ع. عياب التخطيط الفعال الذي ييتعد عن ممارسـات فعلية للاستفادة من النفايـات و إعادة الاستخدام.

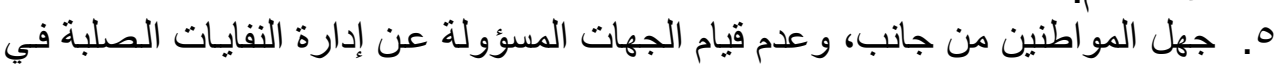

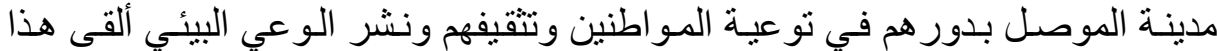

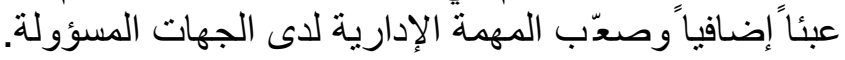

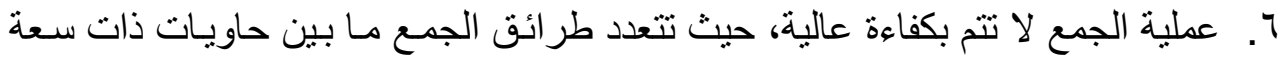

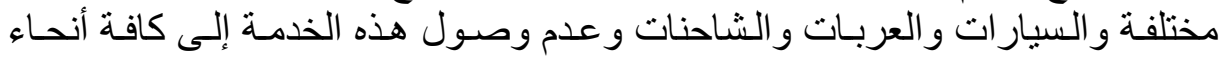


الدينة جعل بعض المناطق تعتمد طر ائق ليست ذات كفاءة في جمع ونقل و التخلص من النفايات الصلبة.

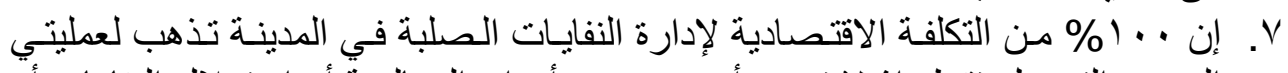

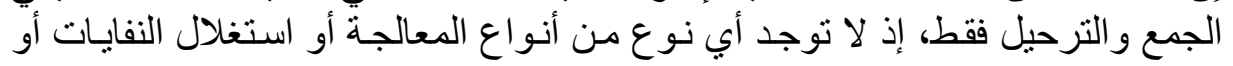
حتى إعادة تدوير ها واستخدامها.

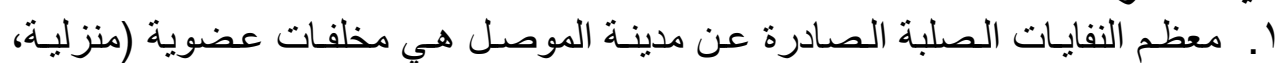

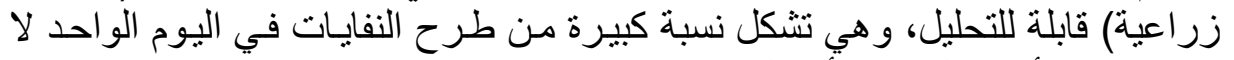

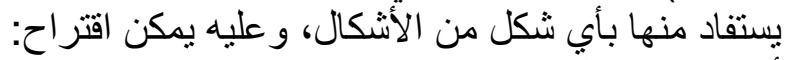

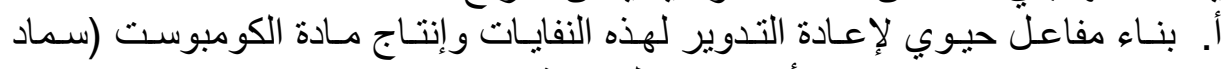

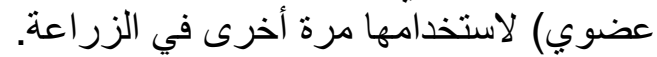

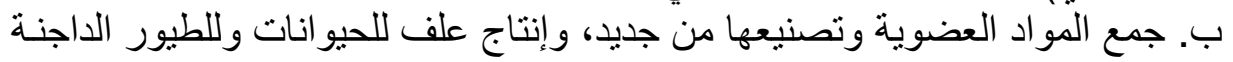
التي تربى في مدينة الموصل على لئى نطاق واسع.

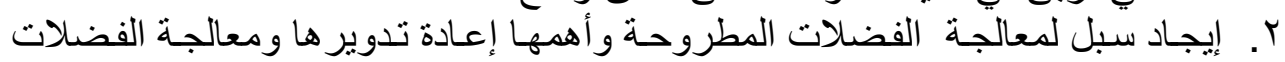

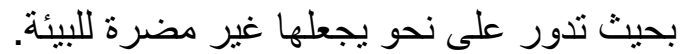
r. عدم التهاون في ترك و وإهمال معالجة النفايات، لأن تأثئثر هذه النفايات سلبي على البيئة وبالتالي هو ضرر عام ترف يمس المجتمع بأكمله.

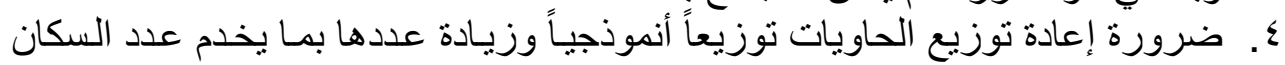

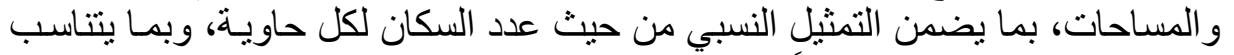

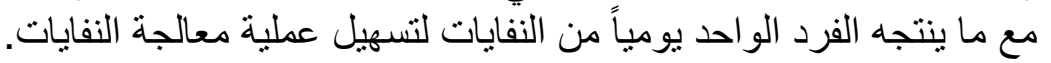

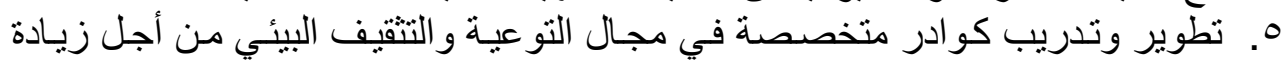

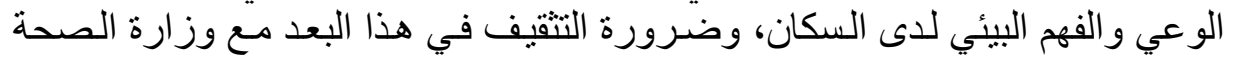

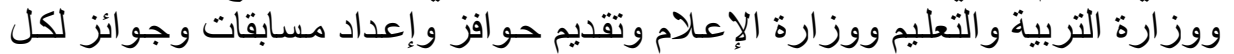
1.

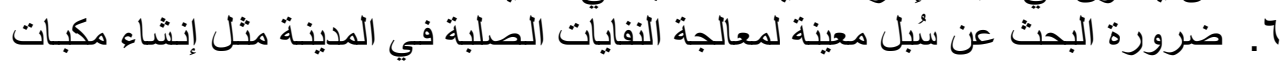

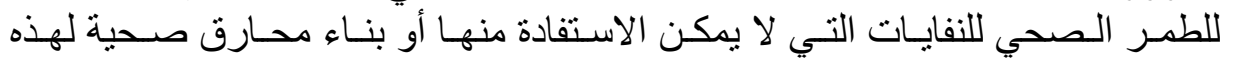
النفايات بحيث لا تضر سلامة البيئة وصحة المجتمع.

\section{أولاًٍ المر اجع باللغة العربية}

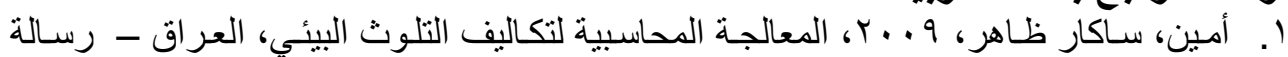

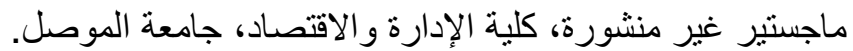

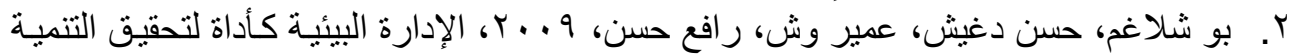

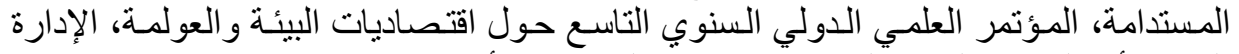
البيئية كأداة لتحقيق التنمية الكستدامة، جامعة الزيتونة، الأردن. 


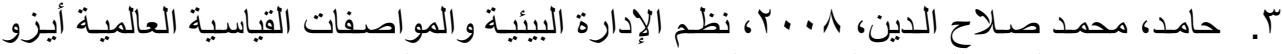

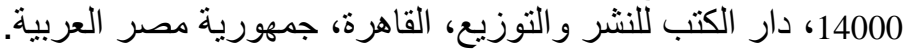

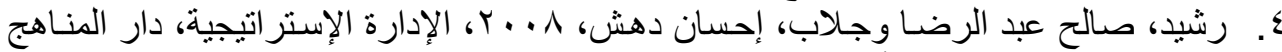

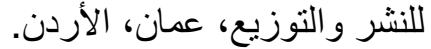

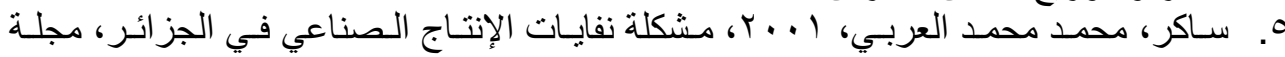

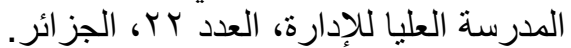

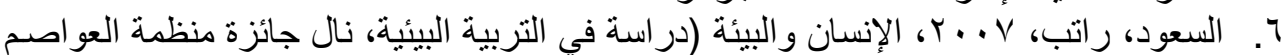

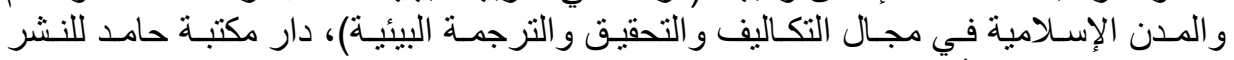

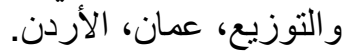

V. صباريني، محمد، والحمد، رشيد، ـ99 19، الإنسان و البيئة التربية البيئية، مكتبة الكتاني، اربد،

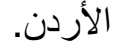

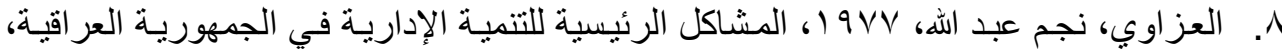

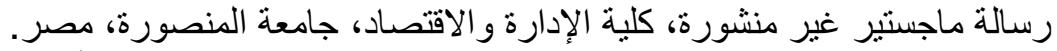

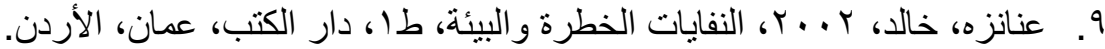

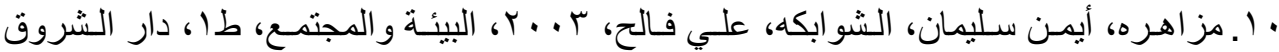

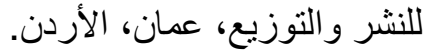

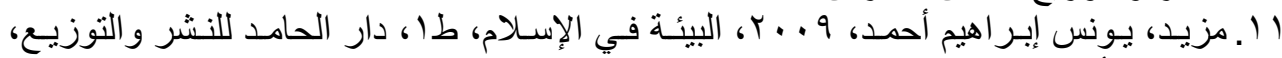

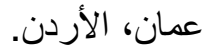

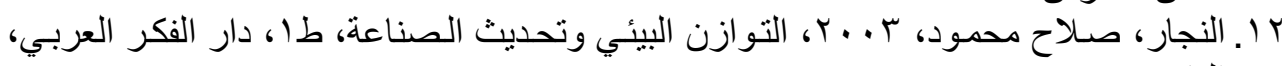

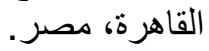

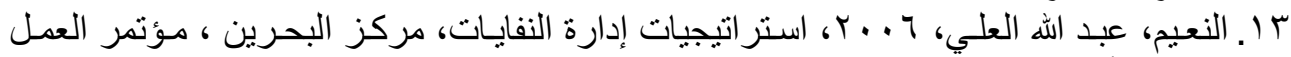
البلاي الأول، الرياض، السئل السعودية.

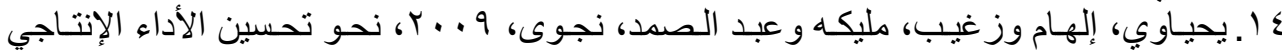

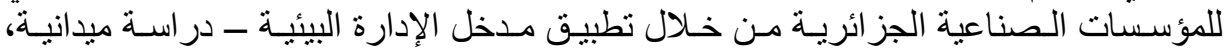

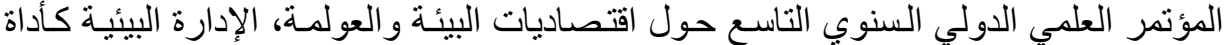
لتحقيق التنمية المستدامة، جامعة الزيتوبنة التئة الأردن.

\section{ثانياً - المراجع باللغة الأجنبية}

1. Diaz, L., Savage, A., M., Eggerthl. L, 2005, Waste-Mange, 25, 6:626 -637.

2. Enrigue Sierra, 1996, The New ISO14000 What Exporters Shoud ISO Management System Know, International Trade Foran, No. 3.

3. Hennery, Danniel, ET. Al, 1989, Managing The Environmental Crisis, Duke University Press London.

4. UNEP, 2001-2003, united National Environment Program.

5. Ved, 1998, ISO 14000 An Approach to Environmental Management, Chemical Business, Vol. 12, Issue 3.

$$
\begin{aligned}
& \text { ثالثاً الانترنت }
\end{aligned}
$$

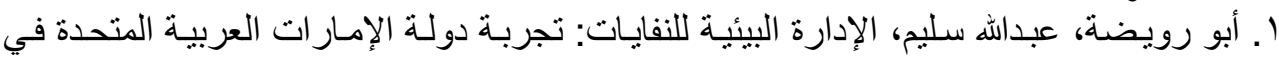

$$
\begin{aligned}
& \text { تدوير النفايات الصلبة و إعادة استخدامها. }
\end{aligned}
$$

http://www.wildlife-pal.org/Environment.html,2007.

r. الثرياني، أحمد بن علي، تشريعات إدارة النفايات في دول مجلس التعاون الخليجي. www.publcations Ksu-edu.sa/conferences/articleolqdoc. 


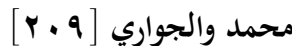

http://www4eco.com/2004/11/99htm-5K

$$
\text { r. محمود، عبدالحكيم، أخبار البيئة، على الموقع: }
$$

http://www.environment.gover.Jo/Societyencyelopadia/Scjor.htm

File://I:/government-news=136242htm.

www.bab.com

$$
\text { ع. بارود، نعيم سلمان، } 1 \text {. . Y، إدارة النفايات الصلبة، في محافظة قطاع شمال غزة: }
$$
www.iugaza.edu.ps/emp/emp-folek ers/328/nefoye t3doc.

5. Alan, 2009, www.anr.state.vt.usldec-wastediv/solid/pubs/VT/swm gmt plan.pdf. 6. Meat Processing EMS Guide, 2001, Getting Started, www.iwrc. cov/Programs. 